\title{
A RADIOBEACON AND RECEIVING SYSTEM FOR BLIND LANDING OF AIRCRAFT
}

\author{
By H. Diamond and F. W. Dunmore
}

\section{ABSTRACT}

A radiobeacon and receiving system is described for use at airports to permit the blind landing of aircraft under conditions of no visibility. The system comprises three elements to indicate to the pilot the position of the aircraft as it approaches and reaches the instant of landing. Lateral position (that is, landing field runway direction) is given by a small directive beacon of the same type as employed for guidance on the airways, differing only in the use of smaller loop antennas and lower power. Longitudinal position along the runway (that is, approach) is given by a marker beacon. Height is given by an inclined ultrahigh-frequency radio beam, used in such a way as to provide a very convenient gliding path for the landing airplane, free of all danger from obstructions.

The same medium-frequency receiving set required for obtaining radiotelephone and radio range beacon service on the airways is utilized for receiving the runway localizing and marker beacon signals. The course indications of the runway localizing beacon are observed on the same vibrating reed indicator as employed on the main radio range beacon, automatic control of receiving set sensitivity being provided to maintain substantially constant reed deflections regardless of the distance between airplane and transmitting station. The marker beacon indications are received aurally. A special high-frequency receiving set is required to receive the landing beam signals. The rectified output current of this set is passed through a d. c. microammeter mounted on the instrument board. By keeping the deflection of this microammeter at a fixed value, the pilot directs the airplane along the curved path coinciding with the line of equal intensity of received signal below the axis of the beam. The relative position of the airplane with respect to this convenient landing path is indicated by the rise or fall of the microammeter deflection above the fixed value.

\section{CONTENTS}

I. Introduction

1. The need for this development

2. Previous work

(a) Field localizers

(b) Landing altimeters

II. Radio system of blind landing aids, first arrangement

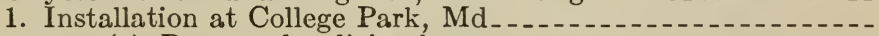

(a) Runway localizing beacon

(b) Boundary marker beacon

2. Demonstrations by Guggenheim fund

(a) Special navigation instruments, altitude indication.--

III. Radio system of blind landing aids, improved arrangement._...-

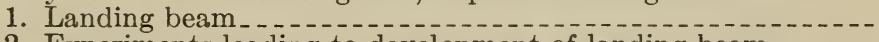

2. Experiments leading to development of landing beam

3. Other improvements .............

(a) Runway localizing beacon

(b) Boundary marker beacon

4. Use of the improved system .

5. Further developments
(a) Runway localizing beacon

(b) Boundary marker beacon

(c) Expansion of system to take care of wind direction. 
IV. Description and operation of apparatus

1. Runway localizing beacon

2. Boundary marker beacon

3. Receiving system for localizing and marker beacon signals.-- 919

4. Landing beam ........ 923

(a) Theory of operation 923

(b) Directive transmitting antenna system

(c) The ultra-high-frequency transmitting circuit ar-

(d) The receiving system

V. Practical applications

VI. Acknowledgment

\section{INTRODUCTION}

This paper describes the research on a radio system for the blind landing of aircraft carried on in the research division of the Aeronautics Branch of the Department of Commerce at the National Bureau of Standards, during 1928 to 1930.

The object of the research was to provide a simple and effective radio system which, when combined with the usual navigational instruments, would permit the safe landing of aircraft in fog or any condition of visibility or no visibility. This system was to be adaptable for use in conjunction with the radio navigational aids being provided for point-to-point flying on the civil airways of the United States. In accordance with the practice already adopted in the development of the navigational aids for the civil airways, all the complicated and expensive parts of the system were to be used on the ground, the equipment required on the aircraft being kept as simple as possible.

The system developed fulfills these requirements. The pilot receives the desired information with a minimum of effort on his part. The additional equipment required on the aircraft (for use of the blind landing aids) is very simple, weighing approximately 15 pounds.

\section{THE NEED FOR THIS DEVELOPMENT}

The practicability of the use of directional radio as an aid to pointto-point flying has been demonstrated by nearly two years of service given by the radio range beacon system on the fixed airways. By means of this system ${ }^{1}$ the pilot can keep accurately on his course, know approximately the points he is fiying over, and proceed unerringly to his destination. Scheduled air transport operation is thus immeasurably aided; many flights are made which could not possibly be made without the use of radio direction facilities. Nevertheless, interruption of scheduled flying is still the rule whenever the landing field lies in an area completely inclosed by fog. The results secured by the development of instrument flying and radio navigational aids are then nullified through the lack of means for safe landing at the desired destination, under conditions of poor visibility. The system of radio aids to blind landing described in this paper removes this last great hazard to the reliability of airplane travel, and insures the rigorous maintenance of scheduled flying by day or night.

1. J. П. Dellinger and II. Pratt, Develonment of Radio Aids to Air Navigation, Proc. I. R. F., 16, p. 890; July, 1929. II.J. Walls, Tho ('ivil $\Lambda$ irways and Their Radio Facilities, Proc. I. R. E., 17, 1). 2141 ; Decemher, 1989. I. IT. Dellinger, IT. Diammel, and $\mathrm{H}$. W. I) Immoro, Dovelopment of the Visual Typo Rasdiobeacous system, B. S. Juur. LescarcL, 1 (L1'159), 1). 125; March, 1930; Proc. 1. L. L., 15, p. 796; May, 1930. 


\section{PREVIOUS WORK}

The present development differs from much of the earlier work in this field in its emphasis on directional radio transmission, thereby simplifying the receiving installation on the airplane. A system of blind landing aids must, in general, indicate to the pilot the position of the aircraft in three dimensions as it approaches and reaches the instant of landing. In practically all previous experimentation this problem has been resolved into two separate problems; namely, field localizing and means for securing suitable height indication.

\section{(a) FIELD LOCALIZERS}

The arrangement usually adopted for field localizing has involved the use of "leader cables." Typical installations are those of the British Government at Farnborough ${ }^{2}$ and of the French Government at Chartres. The British installation employs a complete circuit around the landing field with a visual indicating device on the airplane instrument board. The French installation uses straight cables. The Loth Co., of Paris, and several agencies in this country, including the United States Air Corps at Wright Field, Dayton, Ohio, and the Ford Motor Co. at Detroit, Mich., are experimenting with various arrangements employing leader cables.

An obvious disadvantage of the leader-cable method of field localizing is its great cost. This method generally involved the burying of cables outside the limits of the landing field, thereby introducing the expense of securing right of way, in addition to the actual cost of equipment and installation.

\section{(b) LANDING ALTIMETERS}

In several of the leader-cable systems, the diminution of intensity of the magnetic field surrounding the cable for increasing distance from the cable is utilized for securing altitude indication. Theoretically, the intensity of the magnetic field varies inversely as the height above the cable. A suitable instrument on the airplane used for measuring the magnetic field intensity may therefore be calibrated directly in height above ground. Accurate altitude indication is then obtained, provided the airplane is neither banking nor turning when passing over the cable. This condition is rather difficult to achieve during blind flight, particularly since the airplane is at the same time being maneurered to maintain a definite "course" in accordance with signals received from the leader-cable system. A second difficulty exists in the necessity for the instrument to have the same calibration for all landing fields. This requires close equality of the magnetic field intensities at different installations, and also requires that no distortion of the shape of the magnetic field exist.

The problem of securing reliable altitude indication, particularly during the last few hundred feet above ground, is a difficult one. The barometric altimeter, in common use on aircraft, is inadequate for the purpose, since it indicates primarily air pressure and not height above the ground.

Experiments are being undertaken by a number of organizations looking toward the development by several means of altimeters indicating the absolute height above ground. One is the development

2 H. Cooch, J. Royal Aeronautical Soc., 30, p. 365; 1926. 
of a sonic altimeter. ${ }^{3}$ The time taken by sound to reach the ground and return to the airplane is measured. Knowing the velocity of sound, the height of the airplane above ground may be determined. Another device is the capacity altimeter ${ }^{4}$ which measures the distance from the ground by detecting the change in the electrical capacity between two plates on the airplane as the airplane approaches the ground. A third method is by the use of direct reflection with radio waves. ${ }^{5}$ It is doubtful at the present time whether any of these instruments will be sufficiently sensitive or accurate for making normal landings in dense fog. These instruments when available will, however, be exceedingly valuable in maintaining a safe altitude during point-to-point flying, and may prove of some service during landing operations, as will appear below.

\section{RADIO SYSTEM OF BLIND LANDING AIDS, FIRST ARRANGEMENT}

The success obtained with the radio range beacon system in its application to point-to-point flying early suggested its possibilities as a field localizer. With the main beacon used for guiding an airplane to a given landing field, a low-power beacon with small loop antennas could be employed for marking out the major, or any desirable axis of the landing field. A low-power marker beacon could then be used for defining the hazard-free approach to the field (along the axis or runway selected), and for indicating the longitudinal position of the aircraft along that runway. This system offered two outstanding advantages: (1) The same equipment required on the airplane for utilizing the radio navigational aids on the fixed airways was sufficient for the reception of the signals from the runway localizing beacon and marker beacons; (2) the ground equipment was comparatively simple and inexpensive, a transmitter of moderate power for the runway localizing beacon being adequate for marking out a course for a distance range of approximately 15 miles. The marker beacon power requirements were also very small. In addition, all apparatus could be kept within the confines of the airport.

\section{INSTALLATION AT COLLEGE PARK, MD.}

The bureau accordingly began the installation of a system of this type at College Park, Md., in order to test its practicability. A series of flight tests demonstrated its complete feasibility for landing field localization. The problem of altitude indication still required solution at the time of these early tests.

Figure 1 illustrates the layout of the ground tansmitting equipment in this radio system for field localization. The $2 \mathrm{kw}$ directive radiobeacon, with large loop antennas, shown at $A$, is the main radio range beacon of the type provided by the United States Department of Commerce for point-to-point flying on the fixed airways. This beacon is normally located just off the airport (so that the loop antennas may not constitute an obstruction to flying), and serves to

\footnotetext{
'Das Behmlot und seine Entwicklung als akustischer Höhenmesser für Luftfahrzeuge, A. Behm, Heft. 13, p. 56; May, 1026. Jahrbuch der W'issenshaftlichen Gesellsehaft für Luft fahrt.

1. A. Ifyland, True Altitude Meters, A viatiou, 25, P. 1322; October 27, 1928.

- F. F. W. Alexanderson, Height of Airplane A bove Ground by Radio Echo, Radio Engineering, 9, pp. $34-35$; February, 1929 .
} 
direct an incoming airplane to the vicinity of the airport. Utilizing the zero-signal zone directly over the beacon tower, it is possible to locate this beacon to within 100 to 1,000 feet, depending upon the altitude of the airplane. The drop to zero vibration amplitude of the reeds on his course indicator, therefore, gives the pilot his exact location with respect to the landing field and also with respect to the course radiated by the low-power (200-watt) runway localizing beacon $B$. The localizing beacon, using small loop antennas so that it may be located at one edge of the landing field without constituting an obstruction, directs a course along the major axis of the field. It operates on a radio-frequency separated by 50 to $60 \mathrm{kc}$ from that of the main beacon $A$, thereby preventing interference from the main beacon.

Upon receiving the zero-signal indication when directly over the tower of the main beacon, the pilot retunes his receiving set to the frequency of the localizing beacon and through the use of his compass

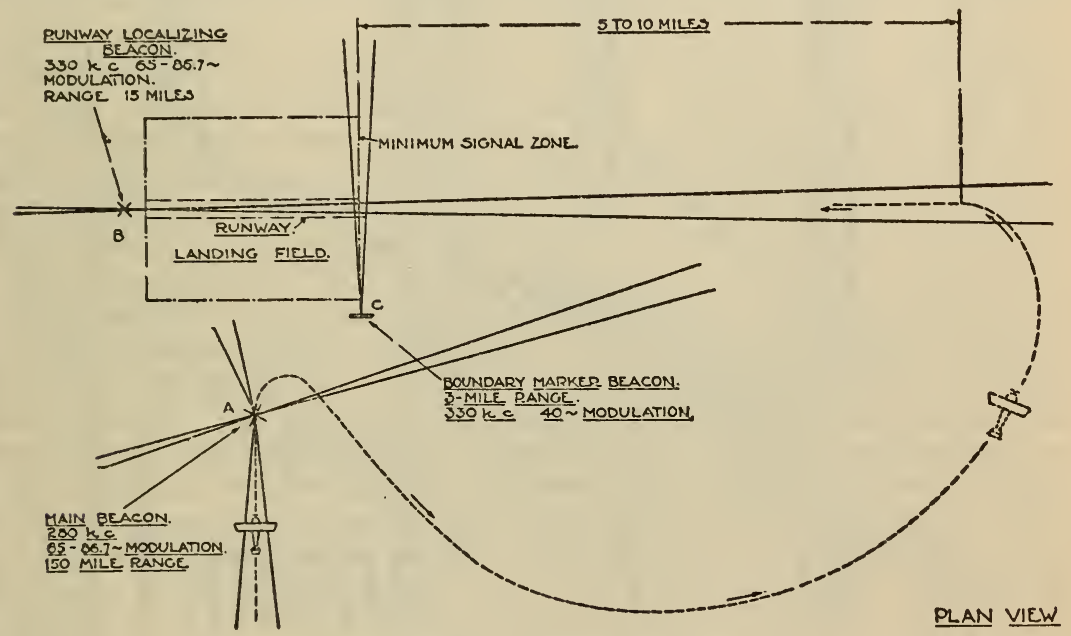

FIGURE 1.-Layout of ground transmitting equipment for radio system of field localization

and knowledge of the geography of the field, orients himself along the major axis of the field. The course indications received on the reed indicator greatly facilitate this maneuver. When crossing the boundary of the landing field a signal from the marker beacon $C$, operating on the same radio-frequency as the localizing beacon $B$, is obtained.

Summarizing, the complete svstem provides course and position indication by means of the main beacon $A$, landing field runway direction by means of the localizing beacon $B$, and longitudinal position (that is, approach) along the runway by means of the marker beacon $C$. On the airplane a simple receiving set is sufficient to receive all these indications. If accurate indications of the absolute height of the airplane above ground could have been secured in the early tests, the complete information necessary for the blind landing of aircraft (in addition to that obtained from the flight instruments) would have become available. 
(a) RUNWAY LOCALIZING BEACON

In the installation at College Park, the main beacon $A$ and the localizing beacon $B$ were of the visual type, the essential difference

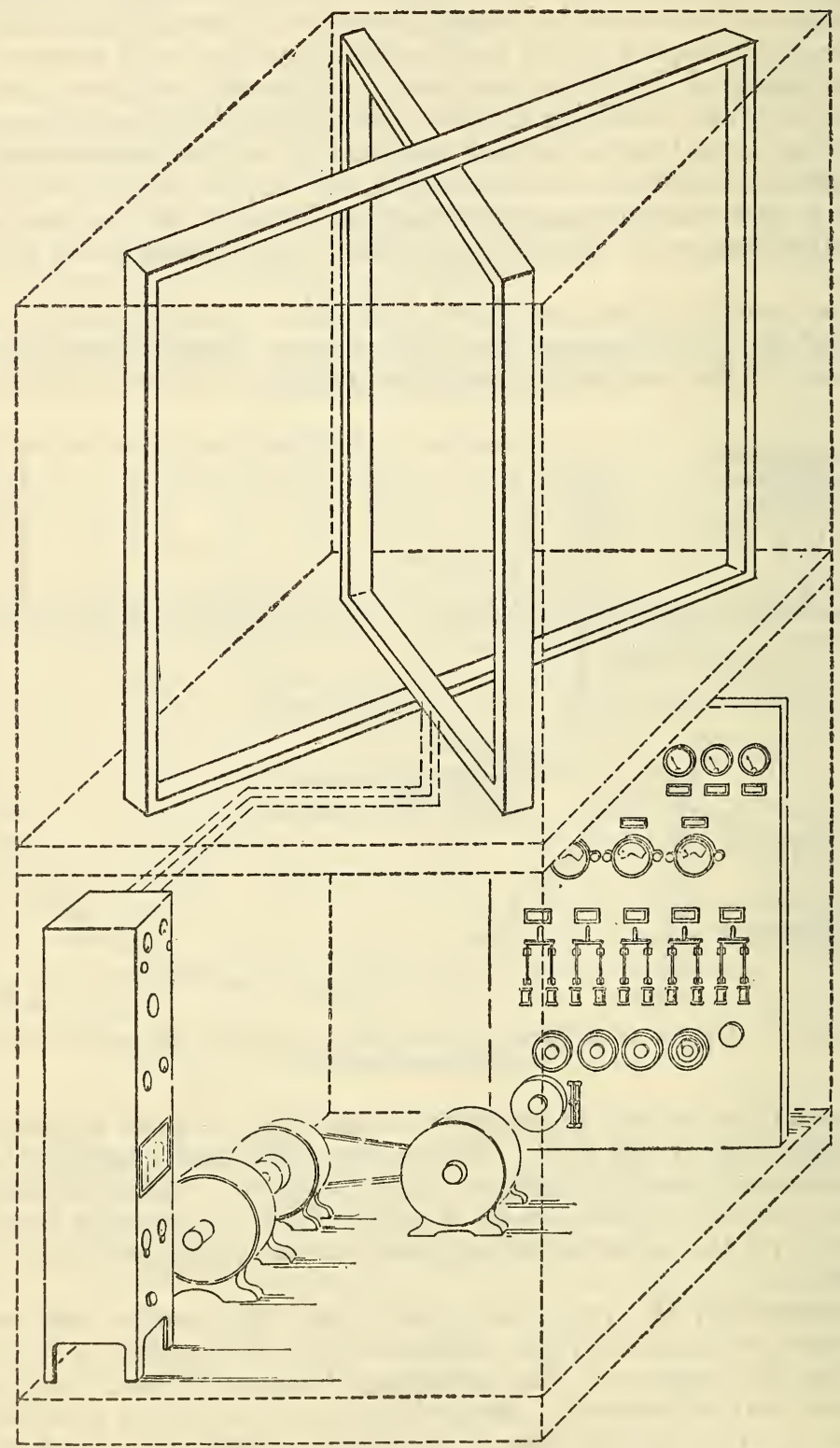

Fraure 2.-Runway localizing beacon sel-up, showing localion of loop anlennas, transmitting set, and power equipment

between the two being the number of beacon courses radiated, the power ratings of the final amplifying stages, and the dimensions of the loop antennas. A description of the visual-type beacon is given 
in the third paper of footnote 1. This publication gives full details of the transmitting system for the main radio range beacon. Some idea of the set-up required for the localizing beacon may be had from the three-dimensional view given in Figure 2. The two loop antennas, crossed at $90^{\circ}$, carry currents of the same carrier frequency but modulated to different low frequencies, 65 and 86.7 cycles, respectively. These antennas are so oriented that the vertical plane containing the major axis of the landing field bisects the angle between the two antennas. An airplane flying in this plane, therefore, receives equal signals from the antennas. On either side of this plane the signal received from one antenna is greater than from the other. On the airplane a visual indicating instrument is employed, ${ }^{6}$ consisting of two vibrating reeds mechanically tuned to the two modulation frequencies of the beacon and actuated by small electromagnets connected in the output circuit of the receiving set employed. When the beacon signals are received, the two reeds vibrate, comparison of their relative amplitudes of vibration serving to indicate the relative amount of signal received from the two loop antennas. On course (that is, along the plane bisecting the angle between the two antennas) the reed vibration amplitudes are equal. Off the course they are unequal, the reed vibrating with the greater amplitude being on the side to which the airplane has deviated. Figure 3 illustrates how the reed indications appear to the pilot, $(a)$ when off the course to the left, $(b)$ when on the course, and $(c)$ when off the course to the right.

By adjusting the time phase displacement between the carrier currents in the two loop antennas, the number of courses provided by the beacon may be made either two or four. The four-course arrangement is more convenient for use on the long-range beacons on the fixed airways. The two-course adjustment is, however, more desirable for the localizing beacon, since in coming in for a landing the presence of the courses at right angles to the runway might prove confusing. A polar diagram corresponding to this adjustment, showing the relative deflections of the two reeds comprising the course indicator as a function of angular deviation from the beacon course, is given in Figure 4.

\section{(b) BOUNDARY MARKER BEACON}

The marker beacon $C$ consisted of a 50 -watt transmitter feeding a roop antenna, oriented as shown in Figure 1. Modulation of the radiated wave to the desired frequency, 40 cycles per second, was obtained by supplying the transmitting tube with a plate voltage of 40-cycle frequency. On the airplane a 40-cycle reed indicator (see fig. 5) connected in series with the main course indicator, was employed. The landing-field boundary line was thus defined by a zero signal zone, $2^{\circ}$ or $3^{\circ}$ wide. The pilot observed an increasing deflection of the marker beacon reed as he approached the edge of the landing field, a decrease to zero deffection as he passed over the boundary line, then an increasing deflection as he came within the landing-field area.

\section{DEMONSTRATIONS BY GUGGENHEIMI FUND}

The practicability of the system of field localization outlined abnve, in application to actual blind landings, was demonstrated by Lieul.

${ }^{6}$ F. W. Dunmore, Design of Tuned-Reed Course Indicators for Aircraft Radiobeacon, B. S. Jour. Research, 1 (RP28); November, 1928. 
J. H. Doolittle, of the Daniel Guggenheim Fund for the Promotion of Aeronautics, in tests carried on at Mitchel Field, Long Island, during July to December, 1929. During the latter part of 1928 the Guggenheim Fund conducted an extensive survey of methods likely to lead to the solution of the problem of landing in fog. The Bureau of Standards submitted a report to the Guggenheim Fund outlining essentially the system described above, and volunteered to make an installation at Mitchel Field similar to the one already under way at College Park. Arrangements for this cooperation were made in January, 1929, the bureau agreeing to install a runway localizing beacan and a

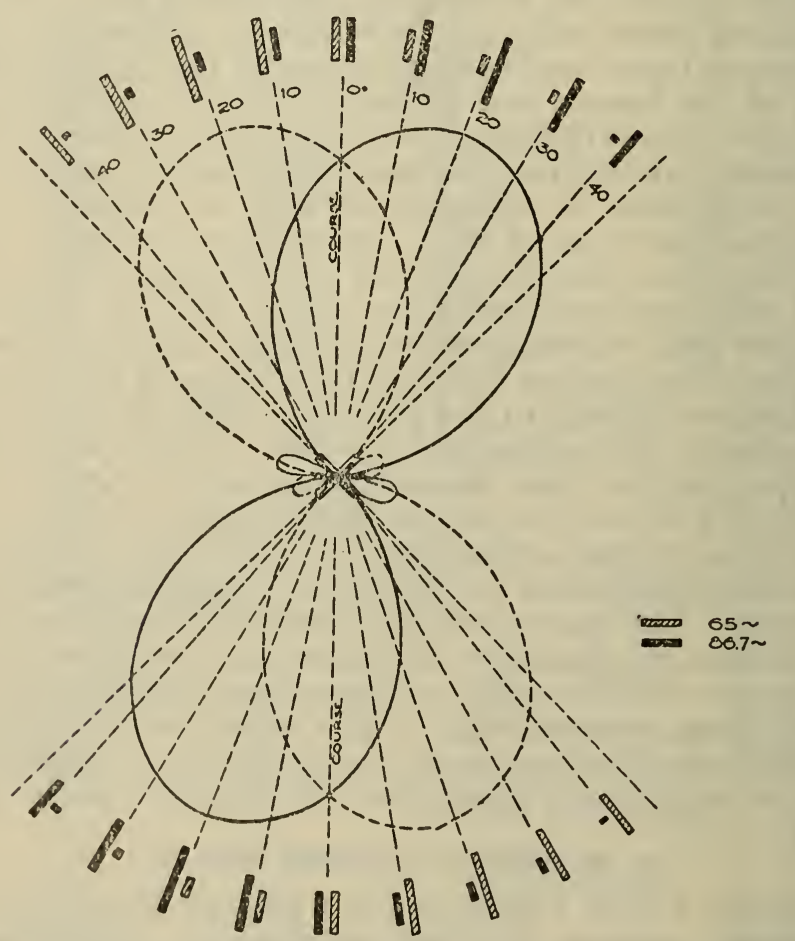

FIgURe 4.-Polar diagram showing relative reed deflections as a function of angular deviation from the runway localizing beacon course

suitable marker bencon. An aural type beacon, installed by the United States Lir Corps, was to serve as the main directive radiobeacon.

'The installation was completed in July, 1929, and was a material factor in enabling Lieutenant Doolittle, seated in a completely inclosed cockpit, to take ofl, circle the field, and make a satisfactory landing. $\Lambda$ brief description ${ }^{7}$ of the method of landing employed is considered of value here, particularly to serve as a basis of requirements for a blind landing system, and also as a comparison with the

7 A complete description is given in the following two pamphlets issued by the Daniel Guggenheim Fund for the Promotion of Aeronautics: (1) Solving the Problem of Fog Flying, 52-page pamphlet; Oct. 9, 1929; (2) Equipment Used in Experiments to Solve the Problem of Fog Flying, 57-page pamphlet; Mar. 1930. 


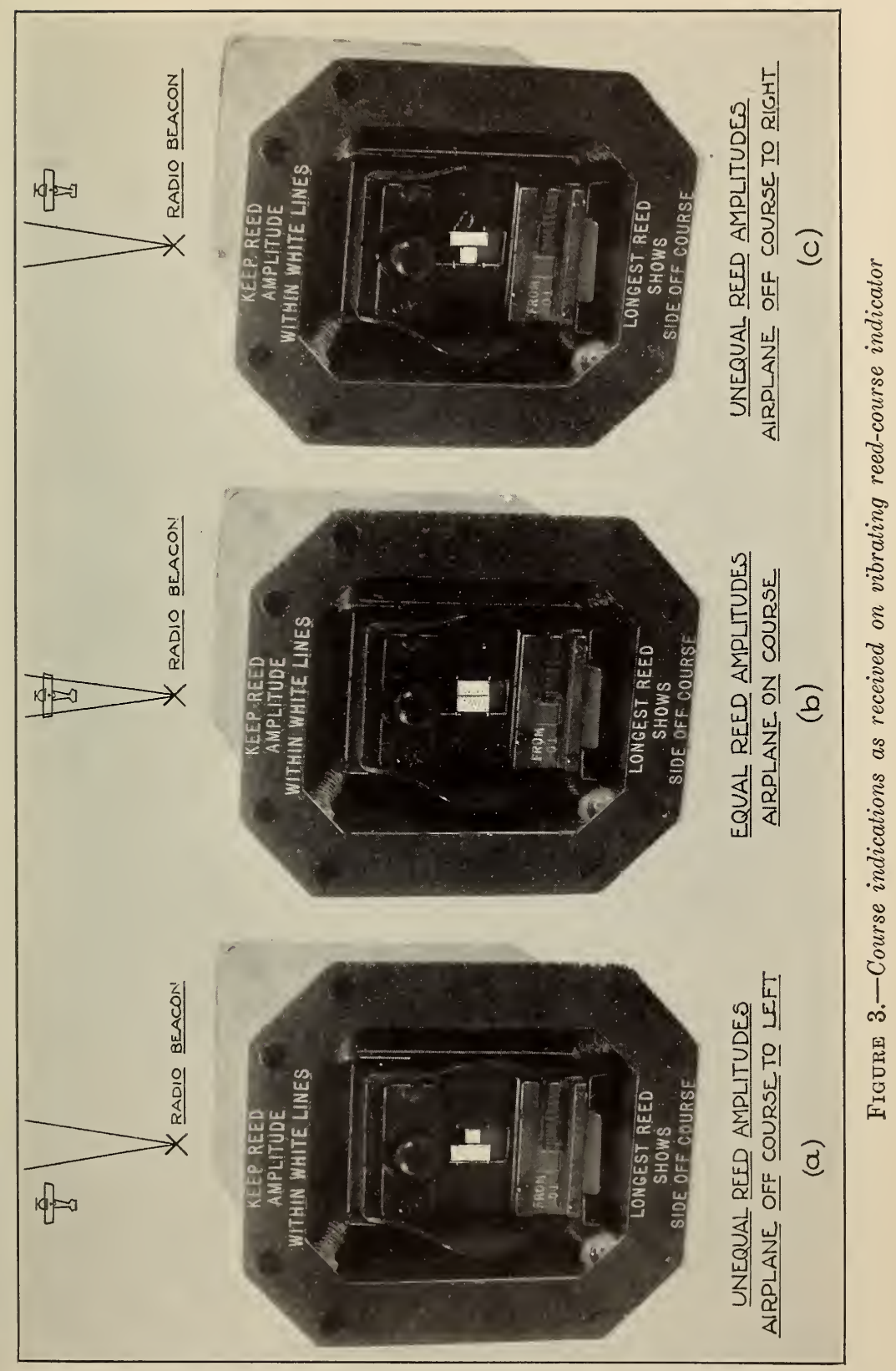


B. S. Journal of Research, RP238

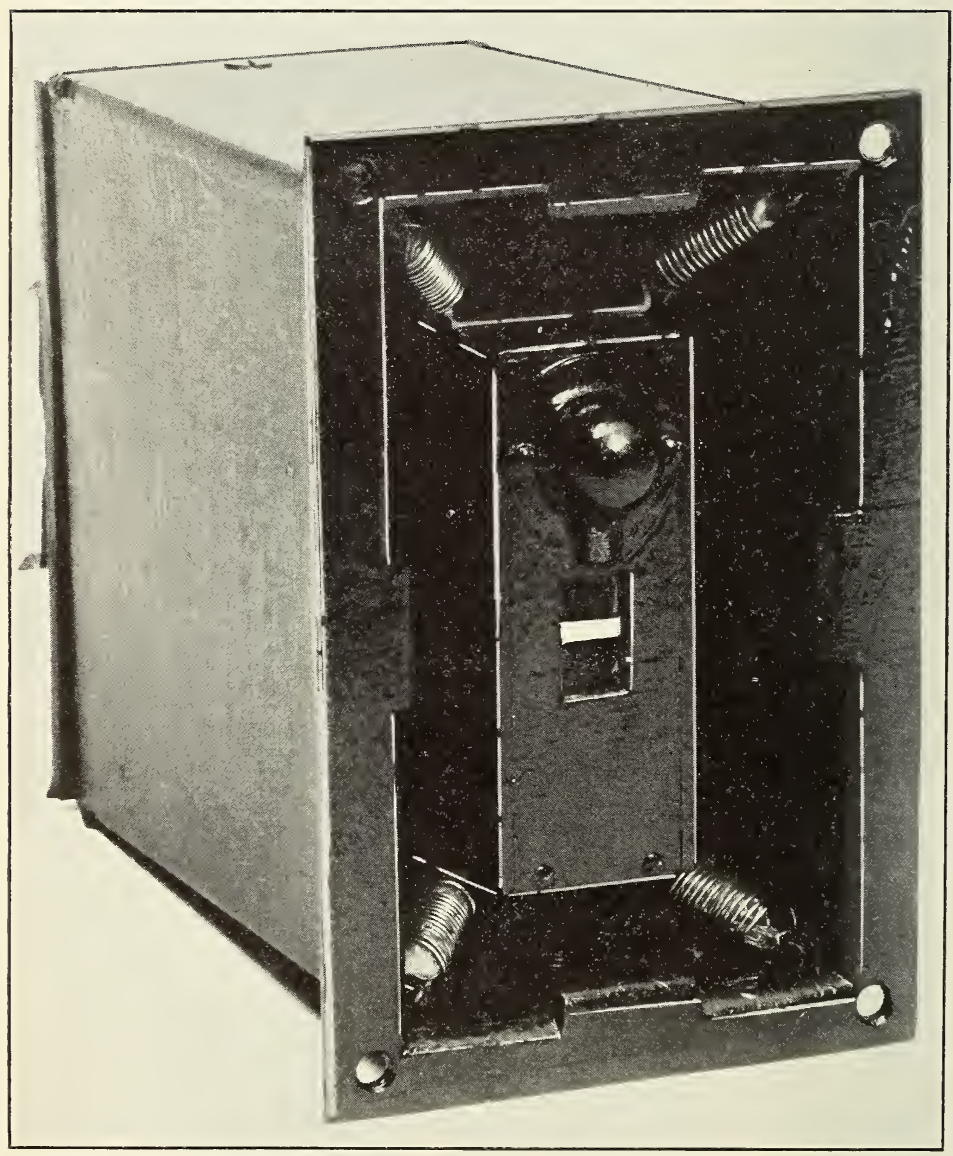

Figure 5.-Marker beacon reed indicator Reed tuned to 40 cycles. 
improved system of radio landing aids more recently developed by the Bureau of Standards at College Park, Md., and described in Section III below.

\section{(a) SPECIAL NAVIGATION INSTRUMENTS, ALTITUDE INDICATION}

In addition to the means for receiving the directional radio aids outlined, the airplane was equipped with standard engine and navigation instruments, including tachometer, compass, bank and turn indicator, air speed indicator, altimeter, rate-of-climb indicator, and three special instruments-an artificial horizon instrument, a directional gyroscope, and a sensitive barometric altimeter with a range of 20,000 feet graduated in 10 -foot intervals.

The artificial horizon instrument gave at all times the attitude of the airplane with respect to the true horizon. The directional gyroscope was employed to maintain a steady course or to change the course by any desired amount. Lieutenant Doolittle used this instrument as an aid to flying on the localizing beacon course. He observed a natural tendency, when the beacon course narrowed, to fly a zig-zag course, first on one side of the beam and then on the other. He was better able to approximate a straight line by utilizing the directional gyroscope for making the necessary slight changes in the course as indicated by the reed indicator.

The sensitive altimeter was designed to secure height indications of the maximum possible accuracy. Provision was made for adjustment of the altimeter in the air, for any apparent change in ground altitude due to a change in barometric pressure, in accordance with information secured through two-way radio communication with the ground. In spite of these precautions, careful tests on the instrument indicated that a probable error of the order of 30 to 40 feet in reading absolute height above the ground was still obtained. The procedure of landing, therefore, resolved itself into maneuvering the airplane into a glide from a position in space of fixed bearing and altitude with respect to the landing field. The glide continued until contact with the earth was made, the oleo landing gear taking up the shock of contact. The lack of knowledge of the absolute height to the necessary accuracy prevented the usual "flattening out" in landing.

The lessons learned from these demonstrations were many. Perhaps the most important was that the problem of securing suitable indications of the true height above ground still required attention. The need for two-way communication with the ground in order to correct the altimeter to the proper barometric pressure seemed excessive. In addition, the absolute height could not be determined to the proper accuracy. When developed, it is probable that one of the absolute type altimeters, described in Section I above, would be preferable to the sensitive barometric altimeter for determining the altitude from which the glide should be started. The accuracy of height indication would probably be increased thereby, and the need for two-way communication with the ground obviated.

\section{RADIO SYSTEM OF BLIND LANDING AIDS, IMPROVED ARRANGEMENT}

Meanwhile, in the experiments carried on at College Park, the Bureau of Standards continued to work on improvements to the radio system of aids to blind landing. A general idea of the operation 
of the improved system developed may be had by reference to the

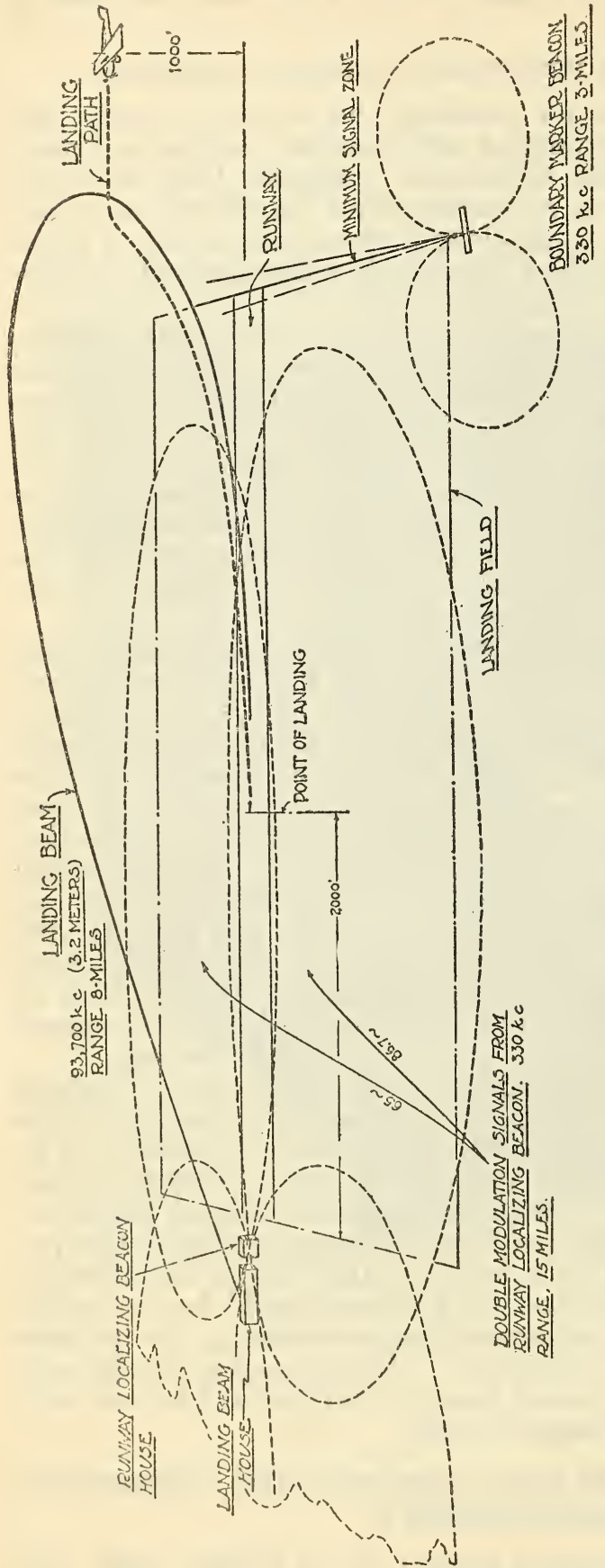

three-dimensional illustration shown in Figure 6 . The main radio range beacon ( $A$, fig. 1$)$ is still employed, though not shown in Figure 6. Lateral position (that is, landing-field runway direction) is still given by a runway localizing beacon, and longitudinal position (that is, approach) by a landingfield boundary-marker beacon. Numerous improvements in the operation and use of these elements have been effected. The major difference from the system illustrated in Figure 1 consists in the means provided for furnishing to the pilot accurate altitude position of the airplane as it approaches and reaches the instant of landing. A landing beam, utilizing directive transmission from the ground, is employed for this purpose.

\section{LANDING BEAMI}

The landing beam transmitter operates on an ultrahigh-frequency of the order of 100 megacycles. The transmitting system employed, including the directive antenna array, is shown in Figure 7. The resultant beam is horizontally polarized, requiring the use of a horizontal doublet antenna on the airplane for its reception. (See

fig. 8.) The beam is directed at a small angle above the horizontal, 


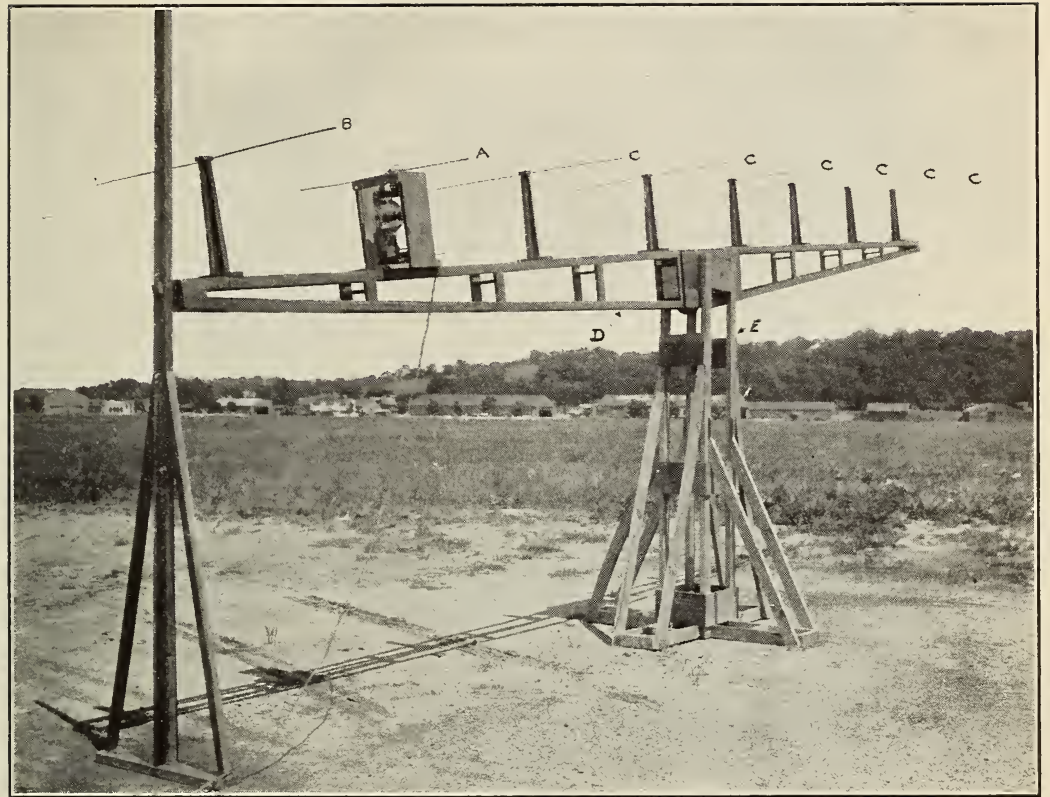

FIGURE 7.-Landing beam transmitting system, showing electron-tube oscillator and directive antenna array

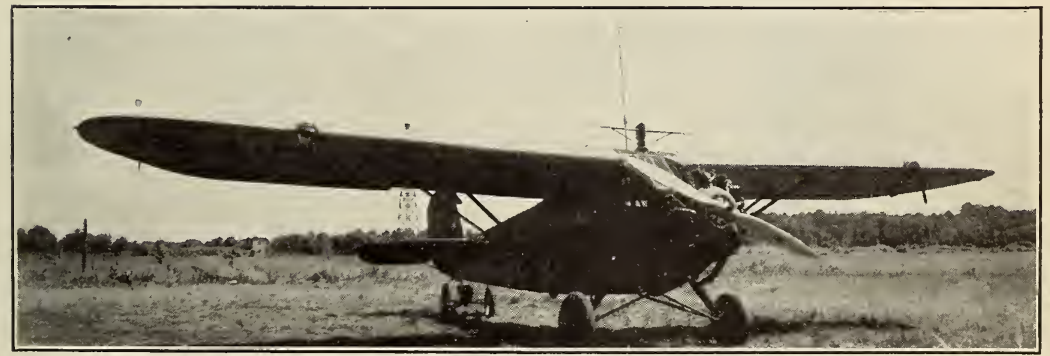

Figure 8.-Bureau of Standards' experimental airplane showing horizontal doublet antenna used for receiving the landing beam signals 


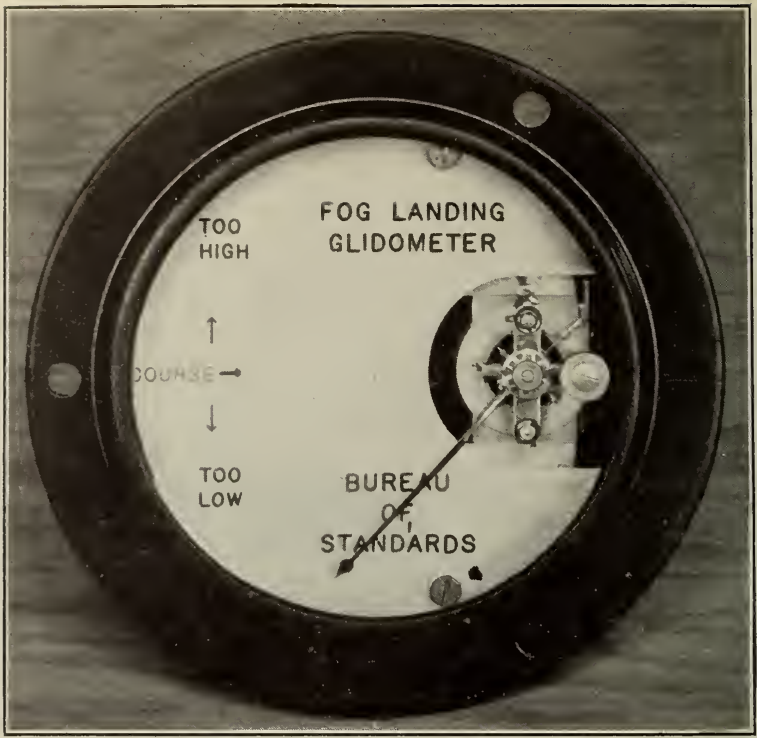

Figure 9.-Landing beam indicator used on the pilot's instrument board to show the relative position of the airplane with respect to the proper landing path

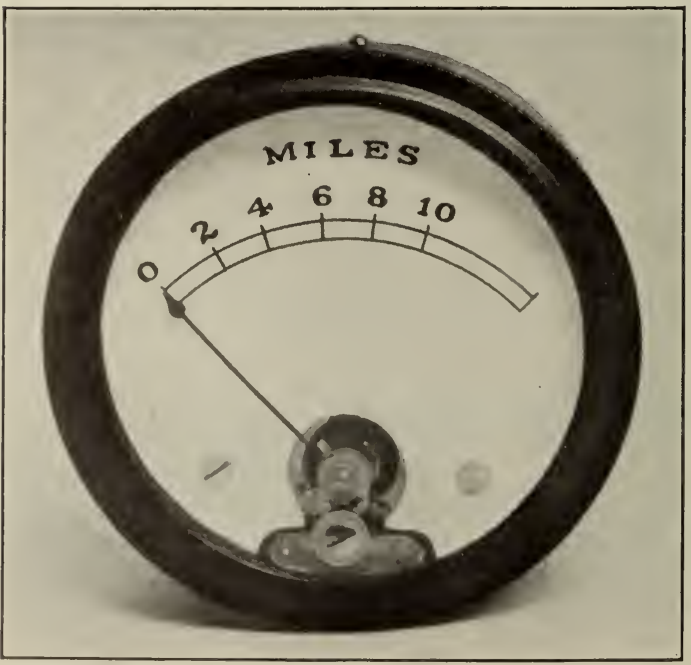

Figure 10.-Rough distance indicator used on the pilot's instrument board to show the approximate distance of the airplane from the runway localizing beacon transmitter 
and is used in such a way as to provide a very convenient gliding path for the landing airplane, beginning at any desired elevation (within, say 500 to 5,000 feet) and at a corresponding distance from the landing field of 2 to 5 miles. Sixty-cycle modulation of the landing beam transmitter is provided to facilitate audio-frequency amplification at the receiving end.

On the airplane, a special high-frequency receiving set is used for receiving the landing beam signals. The signal current in the output circuit of the receiving set is rectified and passed through a $\mathrm{d}$. c. microammeter mounted on the instrument board. The airplane does not fly on the axis of the beam, but on a curved path under the beam whose curvature diminishes as the ground is approached. The path is the line of equal intensity of received signal below the axis of the beam. The diminution of intensity as the airplane drops below the beam axis is compensated by the increase of intensity due to approaching the beam transmitter. Thus, by flying the airplane along such a path as to keep the deflection of the microammeter on the instrument board constant, the pilot comes down to ground on a curved line suitable for landing. Figure 9 shows the microammeter used for the landing beam indications. To facilitate its use by the pilot this instrument is mounted on its side so that the pointer moves vertically rather than horizontally. The deflection to be kept constant is chosen at half-scale reading, the instrument pointer being then in a horizontal position. - A rise of the pointer above this position indicates that the airplane is above the proper landing path, while the reverse is true if the pointer falls below its horizontal position. The indications of the position of the airplane relative to the landing path are thus made readily comprehensible.

Several important advantages obtain for this method of furnishing altitude indication. The landing path may be so directed as to clear all obstructions. The pilot following the landing path is automatically kept above obstructions and no longer needs a thorough knowledge of the terrain in order to effect a safe landing. Secondly, the landing path may be of different shape to suit different landing fields. This is of particular importance in getting into a small field. $A$ third advantage lies in the fact that in the act of following the landing path, the pilot automatically "levels off," thereby facilitating a normal landing, albeit somewhat fast. In following the landing path prior to receiving the marker beacon zero-signal zone, the pilot maintains an air speed somewhat above the landing speed of the airplane, insuring complete controllability with some margin to spare. Upon receiving the marker indication that he is passing over the boundary of the field, the margin over the landing speed may be reduced. The landing is therefore made at a speed more nearly approaching the normal landing speed of the airplane. A fourth advantage is that the landing glide may be begun at any desired altitude, within a rather wide range (say, 500 to 5,000 feet). A fifth advantage arises from the ease of using the landing beam indications. No manipulations on the part of the pilot are required. The tuning is fixed. Since a line of constant field intensity is followed no control of volume is necessary.

\section{EXPERIMENTS LEADING TO DEVELOPMENT OF LANDING BEAM}

At this point, it may be of interest to describe the experiments which led to the development of the landing beam. The object of the

$11295^{\circ}-30-9$ 
first experiments along this line, early in 1929, was to mark out.an equisignal path in space similar to that obtained with the visual-type beacon, but making a constant angle with the horizontal; that is, with the ground. To this end the same transmitting set-up as for the localizing beacon was employed, the two crossed loop antennas being turned over on their sides. This experiment proved unsuccessful because of ground reflection phenomena on the long waves used (about $300 \mathrm{kc}$ ).

The next step was to employ directed waves of higher frequencies. Ultrahigh-frequencies, of the order of 60 to 100 megacycles, were chosen in order to reduce the size of the antenna arrays. Two beams were required, both of the same radio-frequency but each modulated to a different low frequency, and its axis making a different small angle with the horizontal. The equisignal zone would, therefore occur where the two beams intersected; that is, along a line making an angle with the ground intermediate to the two angles formed by the axes of the two beams and ground. It was recognized that some difficulty would be met in setting up the transmitting circuit arrangement necessary for this system, on the ultrahigh-frequencies considered, since a common master oscillator feeding two balanced amplifier branches, each modulated to a different low frequency, was required. Moreover, making use of the equisignal zone, once it was set up, would add another volume control for the pilot to adjust as he approached the point of landing. The construction of suitable apparatus was, however, begun.

It was at this stage of the development that one of the authors ${ }^{8}$ conceived the idea of using only one high-frequency beam in the manner described in Section III, 1, thereby eliminating the technical difficulties noted and at the same time providing a more suitable gliding path for the landing airplane. The obvious simplification of equipment both on the ground and on the airplane led to the adoption of this idea.

\section{OTHER IMPROVEMENTS}

(a) RUNWAY LOCALIZING BEACON

The runway localizing beacon employed in the improved system of blind landing aids, while still operating on the same principles as previously, has been made considerably easier to use. In the installation at Mitchel Field and the early installation at College Park, the equisignal zone or course was found to be somewhat broad, of the order of $4^{\circ}$ to $5^{\circ}$. The use of small, multiturn loop antennas rendered it somewhat difficult to obtain exact $90^{\circ}$ electrical displacement between the two. Some inductive coupling between the two antennas, therefore, existed, tending to broaden the course. The use of a small anticoupling device solved this difficulty, the width of the beacon course being reduced to $2^{\circ}$.

At the receiving end, some difficulty in following the course was experienced owing to the necessity for adjusting the receiving set sensitivity as the airplane approached the beacon transmitter. Since the beacon signals are followed from a distance of 10 miles from the transmitter to approximately 2,000 feet from the transmitter (the 
point of landing), variations in the field intensity of the order of 50 to 1 obtain. Continuous adjustment of the receiving set volume control was therefore necessary, in order to keep the reed deflections within scale. The pilot, in making a landing, is, however, concerned with so many things that keeping the necessary close adjustment of the receiving set sensitivity becomes a troublesome task. To overcome this difficulty, an automatic volume-control device was developed for maintaining essentially constant receiving set output voltage regardless of the magnitude of the input voltage. The use of the runway localizing beacon thereby resolved itself simply to observing the course indications on the reed indicator and maneuvering the airplane to keep on the course.

The design of the automatic volume-control device was affected by the type of boundary marker beacon used, as will appear below. At this point it is sufficient to note that it operates through rectification of the alternating voltage across the reed indicator terminals and application of the rectified voltage, after filtering, as a negative biasing voltage on the grids of the radio-frequency amplifying tubes of the receiving set. An increase in the input voltage to the receiving set normally tending to increase the voltage across the indicator terminals is, therefore, accompanied by an increase in the negative bias on the radio-frequency amplifying tubes and, consequently, by a reduction in the receiving set sensitivity such as to maintain substantially constant voltage across the reed indicator.

The provision of this automatic volume-control device made possible the addition of an important instrument on the airplane instrument board, giving the pilot information as to his approximate distance from the localizing beacon transmitter. Since increasing input voltage to the receiving set is accompanied by increasing negative biasing voltage on the grids of the radio-frequency amplifying tubes, the deflection of a direct-current milliammeter connected in the plate circuit of these tubes will decrease as the airplane approaches the beacon transmitter. This meter (see fig. 10) may, therefore, be calibrated directly in approximate distance from the transmitter. Its calibration will hold roughly on different localizing beacons at different airports, provided these beacons are of approximately the same power ratings. Its chief function is, however, to give the pilot an added check that he is approaching or departing from the landing field and should aid materially in avoiding confusion during blind flight.

\section{(b) BOUNDARY MARKER BEACON}

In the first arrangement of blind landing aids, the boundary marker beacon signals were received on the airplane on a special reed indicator connected in series with the vibrating reed course indicator. Several factors combined to point out that aural indication might prove preferable in this case. The pilot, during landing, must focus attention on a number of instruments giving continuous information as to course, altitude of the airplane, air speed, etc. It was felt that he might easily miss the indications given by the marker beacon reed during the short period when he passed over the landing field boundary line. Aural indication would preclude this possibility. Aural indication also offered a further advantage. The ear is a 
logarithmic device while the reed indicator has a linear response. Proper matching of the powers of the marker beacon and localizing beacon, so that signals from the two may be received at a given point or area for the same sensitivity adjustment of the receiving set, is therefore less exacting when aural marker beacon indications are employed. The marker beacon modulation was, therefore, changed from 40 to 1,000 cycles to facilitate aural reception.

A rather novel requirement comes up in connection with the use of the marker beacon. It will be recalled that the runway localizing and boundary marker beacons both operate on the same carrier frequency, and are both received simultaneously on the medium-frequency receiving set. Using automatic volume control, it is required to hold the voltage across the vibrating reed course indicator constant, while the marker beacon signal must be permitted to vary through a minimum. This requirement was met through the use of a filter circuit arrangement connected in the receiving set output which served to direct frequencies below 200 cycles to the reed indicator and frequencies above that value to the head telephones. The automatic volume control device is connected across the reed indicator terminals as before and, consequently, is operated only by the signals from the localizing beacon (no voltage of 1,000-cycle frequency appearing across the indicator). The 1,000-cycle marker beacon signal heard in the head telephones, since it does not affect the automatic volume control device, is therefore permitted to vary through a minimum, as required.

\section{USE OF THE IMPROVED SYSTEM}

Having outlined the function of each element of the complete system of blind landing aids, it is desirable at this point to consider the apparatus required on the airplane for making use of these aids. Figure 11 shows a complete airplane installation. The medium-frequency receiving set $A$, using mast antenna $B$, is normally employed for the reception of the weather broadcast and radiobeacon services. This set is also used for receiving signals from the runway localizing and marker beacons. To the output of this set is connected the filter unit $C$ which directs the main and localizing beacon signals to the reed indicator $D$, and the boundary marker beacon signals to the head telephones. The automatic volume control device $E$ is connected across the reed indicator terminals, its operation serving to maintain substantially constant reed deflections and at the same time governing the scale reading of the instrument $F$, which indicates roughly the distance from the beacon transmitter.

The receiving set for the reception of the ultrahigh-frequency landing beam signals consists of a detector unit $G$ mounted in the stream-lined housing which supports the receiving dipole antenna structure $I . \quad I$ is the amplifier-rectifier unit. The rectified output current is fed to the landing beam indicator $J$. The remote control panels for the medium-frequency and ultrahigh-frequency sets are shown at $K$ and $L$, respectively. $M$ contains the batteries necessary for operating these sets.

The instrument board on the bureau's experimental airplane is shown in Figure 12 . The reed indicator is shown at $A$, the landing beam indicator at $B$, and the rough distance indicator at $C$. At $D$ 


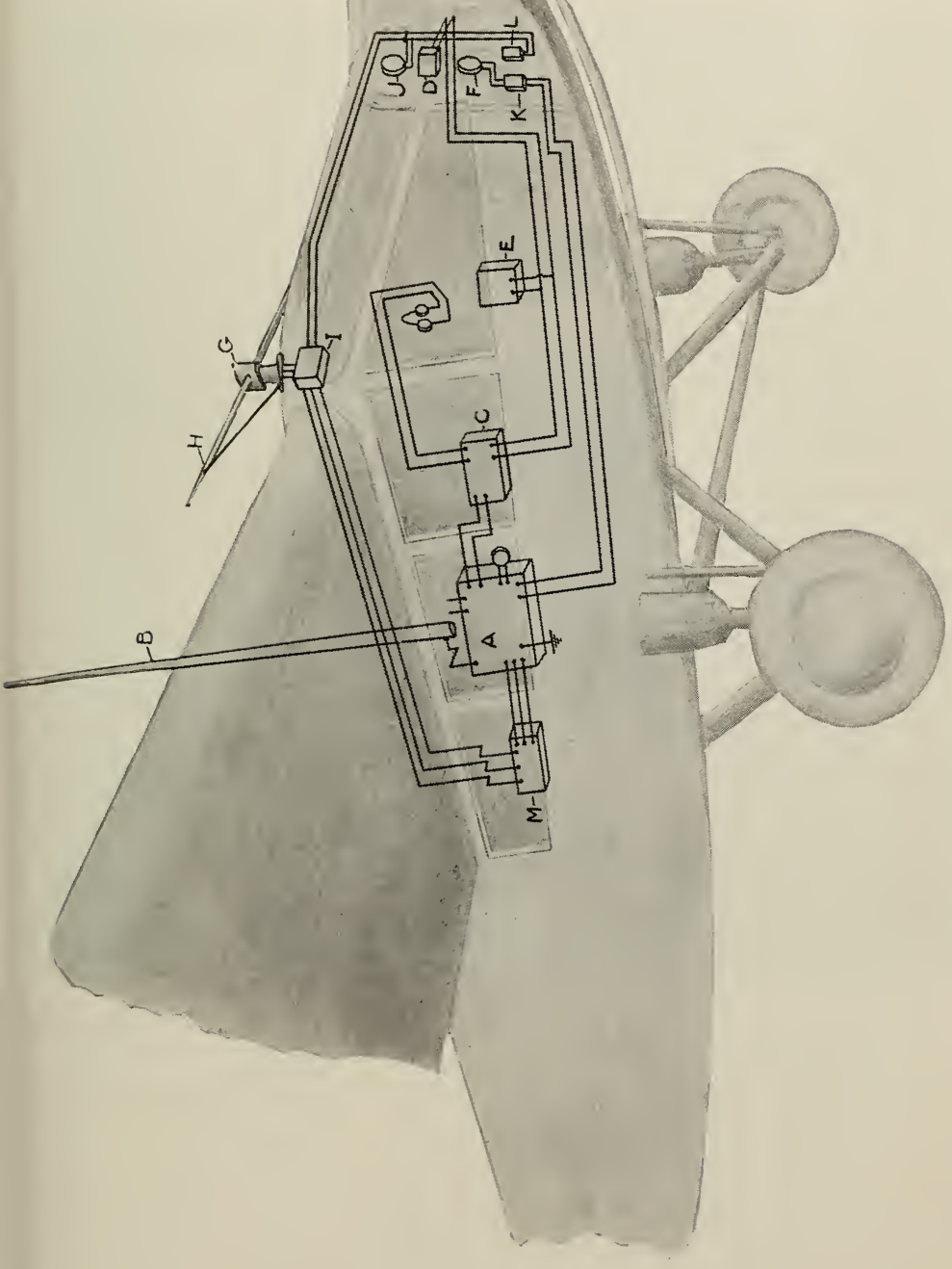

- b

हิ छ्ठैं

क ज

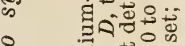

उ

\& $\quad$ v.

- 묭.

$\checkmark$.

\&

2 .

उ.

इ वี००

- 8000

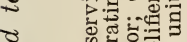

. ¿

કै

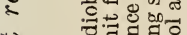

ह

क उ

న్ర

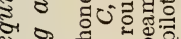

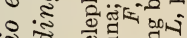

उ

- 웡

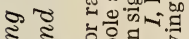

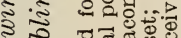

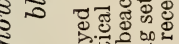

क

ร

ज

ज के 문

क जल

.

-

ह के

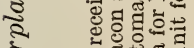

స

8 잉

๘

ह

है हैं

ن

1.

$\exists \quad$ on

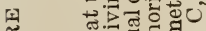

范

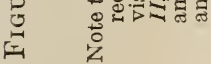




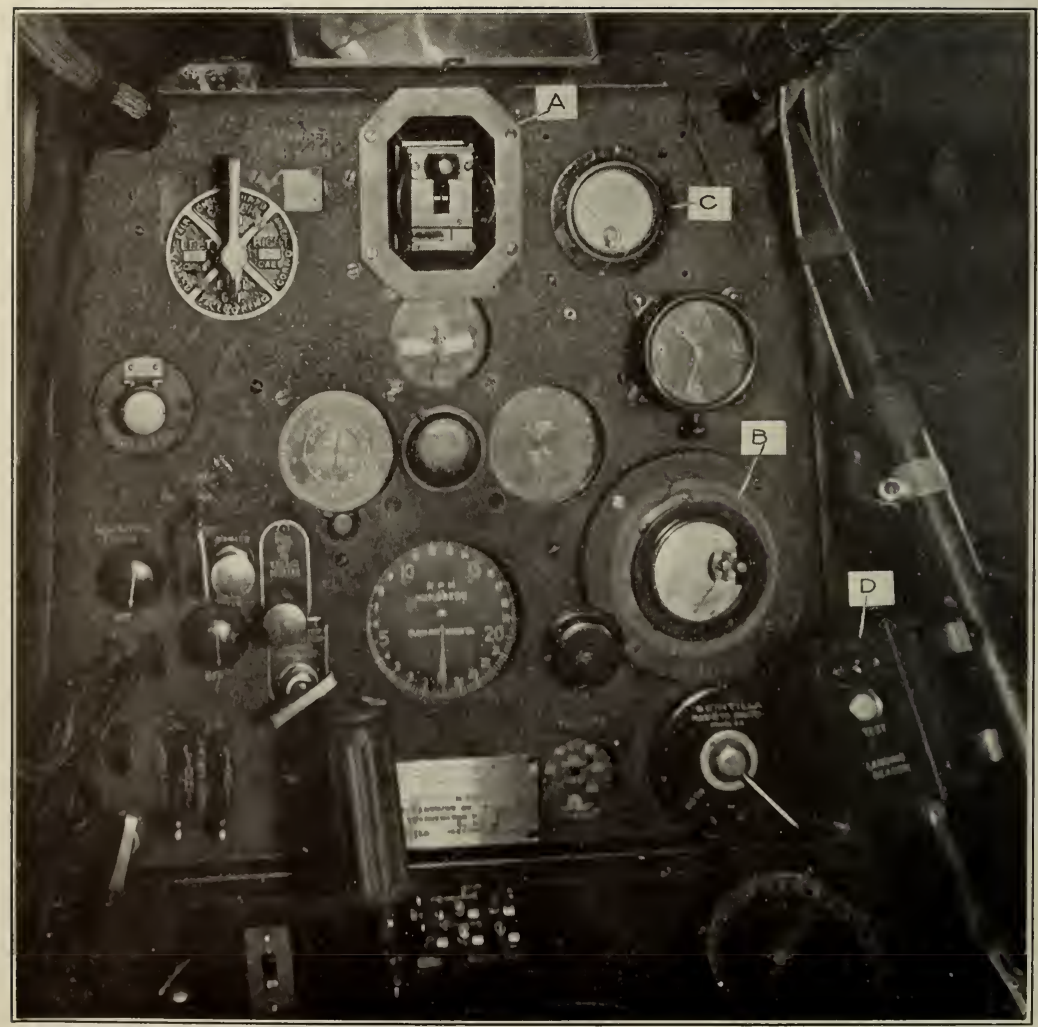

Figure 12.-Instrument board on Bureau of Standards' experimental airplane, showing vibrating reed-course indicator $A$, landing beam indicator $B$, rough distance indicator $C$, and landing beam runway set control and test panel $D$ 
is shown the control panel for the landing beam receiving set. The control panel for the medium-frequency receiving set is not shown.

Let us now consider the operations required on the part of the pilot in making a blind landing. It is assumed that the information necessary for maintaining the airplane in stable flight is available through the use of suitable flight instruments. The medium-frequency receiving set is tuned to the frequency of the main radio range beacon (say, $280 \mathrm{kc}$ ) and indications as to the correct course leading to the vicinity of the airport observed on the reed indicator. Since automatic control of volume is provided, these course indications are available to the pilot without manipulation on his part.

Upon receiving the zero-signal indication when directly over the tower of the main beacon, the pilot retunes the medium-frequency receiving set to the frequency of the localizing beacon (say, $330 \mathrm{kc}$ ) and throws, a switch which places the landing beam receiving set in operation. These are the only adjustments of radio equipment required of the pilot during the entire landing maneuvers. The reed indicator now furnishes information as to the landing field runway direction, the provision of automatic volume control again relieving the pilot of the necessity for adjusting the receiving set sensitivity for variations in the distance between the airplane and the localizing beacon transmitter. The pilot next orients himself along the major axis of the landing field utilizing his compass indications, together with his knowledge of the geography of the field. As noted in connection with Figure 1, the reed indicator aids considerably in this maneuver. The airplane may be kept at any altitude within, say 500 to 5,000 feet. From time to time the pilot glances at the rough distance indicator and endeavors to get on the runway course at a point approximately 5 to 10 miles distant from the landing field. $\mathrm{He}$ now directs his airplane along the runway course and in the direction of the landing field, glancing occasionally at the landing beam indicator. When approximately half the distance to the field is covered, the pointer of the landing beam indicator begins to rise to midscale or horizontal position. When this position is reached, the pilot knows that he is at a point on the gliding path. To follow the gliding path he must maneuver the airplane to keep the pointer in the horizontal position. A pointer position above the horizontal indicates that the airplane is above the proper landing path, while the reverse is true if the pointer swings below the horizontal position.

It is necessary now that the pilot keep accurately on the runway beacon course, at the same time following down on the landing path. To facilitate this, he may reduce the airplane engine speed so that the air-speed indicator registers about 5 miles above the normal landing speed of the airplane. This also helps during the actual landing, as will appear below. The accuracy to which the runway beacon course should be followed is of the order of $\pm 3^{\circ}$. This is necessary in order that the landing beam may be encountered head on; otherwise, a landing path somewhat steeper than the one desired would be followed. It should not prove difficult, however, to follow the course to the necessary accuracy, since a deviation of $\pm 1^{\circ}$ may be observed on the reeds. It is felt that after some training a pilot may correct any tendency to fly a zigzag course by flying slightly off course and gradually bearing in toward the course. 
Some distance from the landing field boundary line the pilot begins to hear a 1,000-cycle signal from the boundary marker beacon. This signal increases gradually, reaches a maximum, then decreases to zero, and begins to increase again. The instant of zero signal defines the landing field boundary line, and for a given field informs the pilot that he is at a definite distance above ground. Neither point of information is, however, essential to the pilot. The chief function of the boundary marker beacon is to establish a transition period after which the landing beam indications become of primary importance. He may now throttle down his engine to landing speed and maneuver his airplane to follow the landing path accurately to the point of landing.

In the foregoing analysis the direction of the wind has been assumed such as to permit landing along the major runway of the field, and in only one direction along that runway. The system as described, therefore, does not take into account the important factor of wind direction. While it is rare that dense fog is accompanied by a strong wind, blizzards and blinding snow storms often offer as great limitations to visibility as fog. The factor of wind direction can not, therefore, be neglected in the general problem of blind landing.

Developments now in progress with a view to making possible landing into the wind regardless of wind direction, will be considered below.

\section{FURTHER DEVELOPMENTS}

In addition to the work on expansion of the system of blind landing aids to take care of wind direction, other experiments are in progress at College Park looking toward still further simplification of the use of the system.

\section{(a) RUNWAY LOCALIZING BEACON}

Since indications of the position of the airplane with respect to the proper landing path are given the pilot by an instrument of the pointer type, it may prove desirable to furnish the localizing beaconcourse indications on the same type of instrument. An instrument of this type has been developed, and numerous successful flight tests made. Whether it will prove superior to the reed indicator for use on the localizing beacon is now being determined. The instrument developed is of the zero-center type (see fig. 13), the movement of the pointer of this instrument from the zero-center position serving to indicate deviation to the left or right of the runway beacon course, as the case may be. The operation of this instrument depends upon the separation of the two frequencies of the doublemodulation signal received from the runway localizing beacon (by means of a suitable filter circuit arrangement connected in the receiving set output), rectification of the separated signals, and the application of the resultant rectified voltages in opposition across the instrument terminals. When the two modulation signals are of equal intensity, as is true on the beacon course, the net voltage applied to the instrument is zero. The instrument pointer then assumes its zero-center position. An increase in relative magnitude of one signal over the other operates to deflect the instrument pointer in one direction or the other, depending upon which signal is the stronger. The direction of movement of the pointer may be made to correspond to the direction of deviation of the airplane from the runway course. 
B. S. Journal of Research, RP238

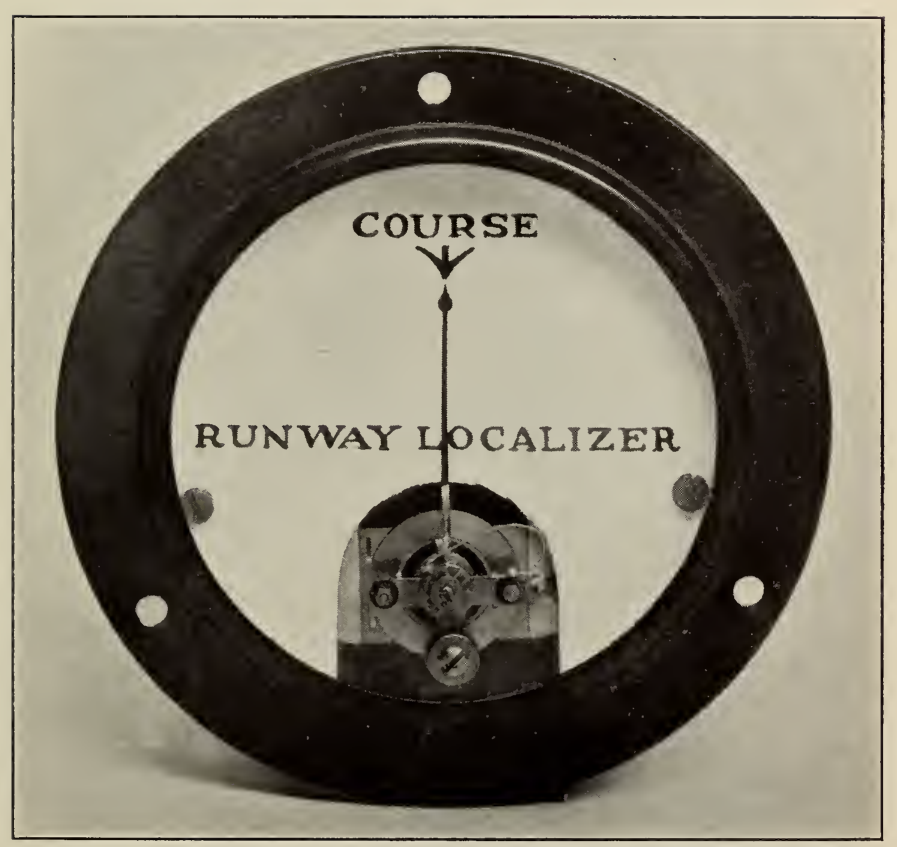

FIGURE 13.-Pointer type localizing beacon course indicator 


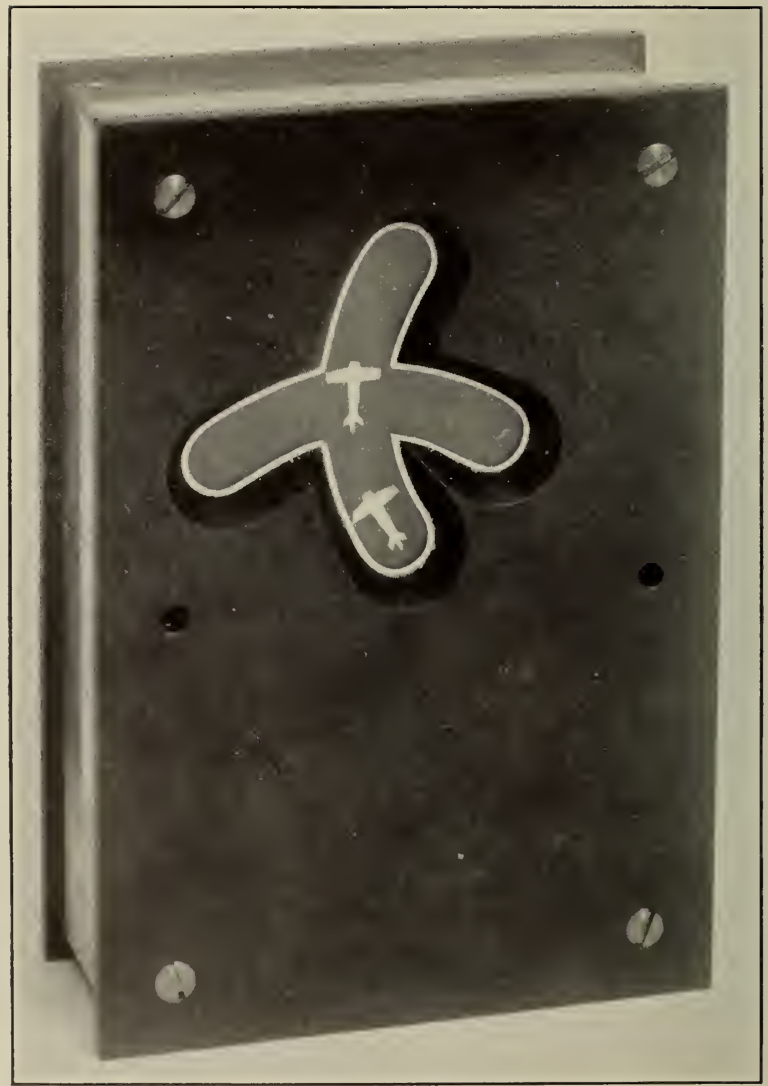

FIGURe 14.-Combined instrument giving indications of the relative position of the airplane with respect to the runway and also with respect to the high-frequency landing beam path 
The use of this instrument presents a number of advantages, and also a number of disadvantages, over the use of the reed indicator. Among the advantages is included the fact that the course indications become considerably sharper, a deviation from the course of the order of $\pm 0.25^{\circ}$ being readily detected. A second advantage is that the sharpness of course is adjustable at the receiving end, and may, therefore, be set at a value found most suitable in actual use. Another advantage is that, since the landing beam and runway localizing beacon indicators are now both of the same type, the two may be combined into a single instrument. (See fig. 14.) The resultant simplification is very similar to that obtained by combining rate-of-climb and bank indications in the artificial horizon instrument. Referring to Figure 14, the small airplane in the center is mounted on the pointer of the zero-center instrument connected to the output of the localizing beacon receiving set. This small airplane moves to the right or left of its central position, depending upon the direction of deviation of the airplane in flight from the runway course. The second small airplane shown on the instrument face is mounted on the pointer of the landing beam indicator, and moves vertically above or below its central position depending upon the position of the airplane in flight with respect to the landing path. During landing the pilot maneuvers his airplane to keep the two miniature airplanes, on the instrument face, exactly over each other and in the central position.

A modification of this indicator face is shown in Figure 15. The small airplane attached to the pointer of the landing beam indicator is here replaced by two yellow ${ }^{9}$ dots. Two reference lines are provided on the face of the instrument, the white vertical line indicating the position of the runway, and the yellow horizontal line the position of the landing path. The position of the airplane during landing with respect to the runway is shown by the relative position of the white minature airplane with respect to the vertical white line. Similarly, the position of the landing airplane with reference to the proper landing path is shown by the relative position of the two yellow dots with respect to the horizontal yellow line. The indications in $A$ show that the airplane is on both courses, while the indications in $B$ show that the airplane is too far to the left and too high.

Among the disadvantages introduced through the use of the pointer-type instrument for securing localizing beacon-course indications is that this type of instrument does not possess the feature of selectivity and consequent freedom from interference inherent in the reed indicator. This disadvantage may be compensated for to some extent by increasing the power of the localizing beacon. A second disadvantage is evident from a study of the polar diagram given in Figure 4. If the small lobes shown are at all irregular, apparent courses may be obtained in a direction at right angles to the desired runway. This would be more serious with the pointer-type instrument than with the reed indicator, since the former depends only upon the balancing of the two modulation signals regardless of magnitude, while the reed deflections on these apparent courses would be too small for use.

\footnotetext{
- In Figure 15, yellow color is denoted by crosshatching.
} 


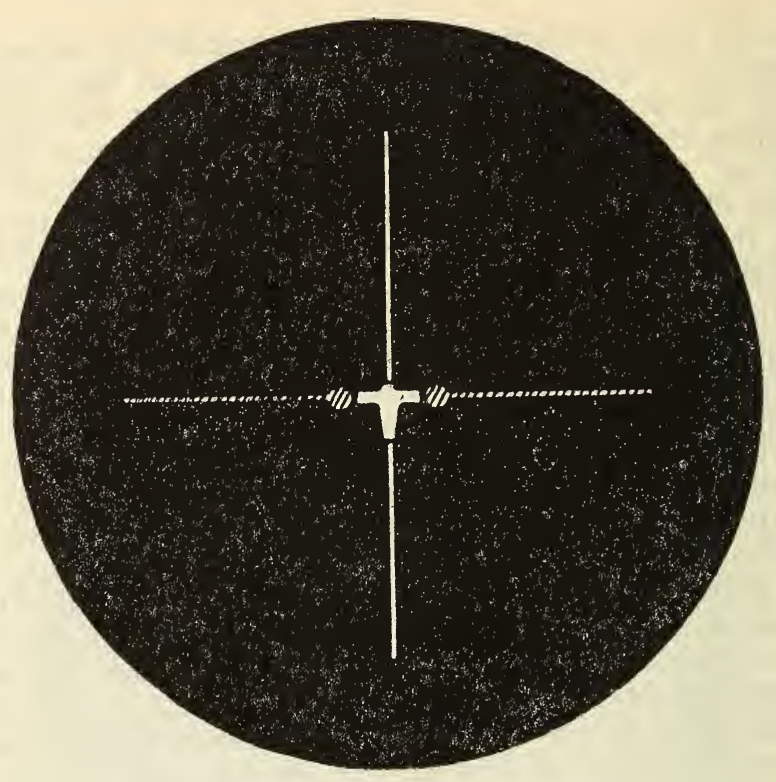

A

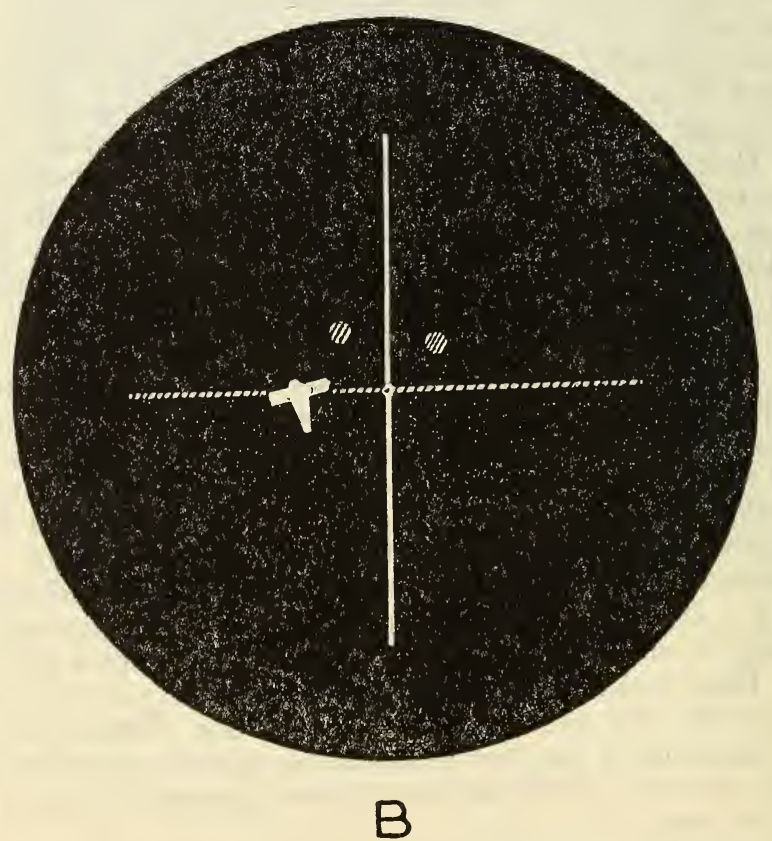

Figure 15.-Modified face for combined localizing beacon and landing beam course indicator 
(b) BOUNDARY MARKER BEACON

A second field for inrestigation is the question of the best type of marker beacon signals to be furnished to the pilot. In the first system of blind landing aids, a 40-cycle reed indicator was employed for this purpose. It was later felt that aural indication would be preferable, since it would prevent any possibility for the pilot to miss the marker beacon indication during the short period when he passed over the marker. So many factors enter into consideration, however, that it is difficult to arrive at a definite decision as to whether aural indication is entirely satisfactory. With the present trend toward combined passenger and mail transportation, it is not possible to visualize the exact conditions on the airplane of the near future. Probably the copilot, who would also be the radio operator, will receive all voice and code messages, including weather reports, while the pilot will use radio only as a navigational aid. In that event, it would be unnecessary for the pilot to use head telephones except if the landing field boundary marker indications were aural. Visual indication, of the nature of a flashing light, such that the pilot could not miss the indications, would then perhaps be preferable. The complete system of radio navigational aids would then be furnished the pilot by visual indicating devices only.

\section{(c) EXPANSION OF SYSTEM TO TAKE CARE OF WIND DIRECTION,}

A number of possible arrangements of the system of blind landing aids outlined above, whereby wind direction may be taken into account, are available. The problem is to determine the most economic arrangement; for example, it has been suggested that the localizing beacon and landing beam transmitters may be buried in the center of the field and oriented into the wind at all times by remote control from the operations office, or even automatically. Aside from the technical problems involved, the provision of a sufficiently large waterproof room with sturdy roof construction level with the surface of the ground, so that an airplane might roll over it, seems economically unfeasible. A second arrangement, somewhat less expensive, would be to mount the localizing beacon and landing beam transmitters on a truck, with provisions for operating the equipment from the 60-cycle supply used for the landing field boundary lights. Service into the wind could then be furnished by moving the truck to the proper position just off the field. In addition to the consideration of costs, each of the two arrangements noted is open to the objection that the landing beam transmitter would require special adjustment in each new position. The shape of the landing path should be convenient for landing and at the same time insure the clearance of all obstructions. Since the obstructions are quite different when coming into the average landing field from different directions, the need for the adjustment of the landing beam transmitter is apparent.

Perhaps the most feasible arrangement is the one shown in Figure 16. The transmitting equipment for both the localizing beacon and landing beam is so simple that the duplication shown appears warranted. It is estimated that the commercial cost of the complete installation would not exceed $\$ 15,000$. An obvious advantage is that the equipment once set up remains in permanent adjustment. 
Referring to Figure 16, the beacon arrangement shown is for a 3-runway ficld. Three-runway localizing beacons, $A, B$, and $C$, and six landing beam transmitters, $D, E, F, G, H$, and $I$, are required. Only three boundary marker beacons, $J, K$, and $L$, are necessary, since the drop in reed deflections directly over the localizing beacons, $A, B$, and $C$, may be used for that purpose in the three remaining positions where marker beacons are required. At any given time but one localizing beacon, one landing beam transmitter, and one

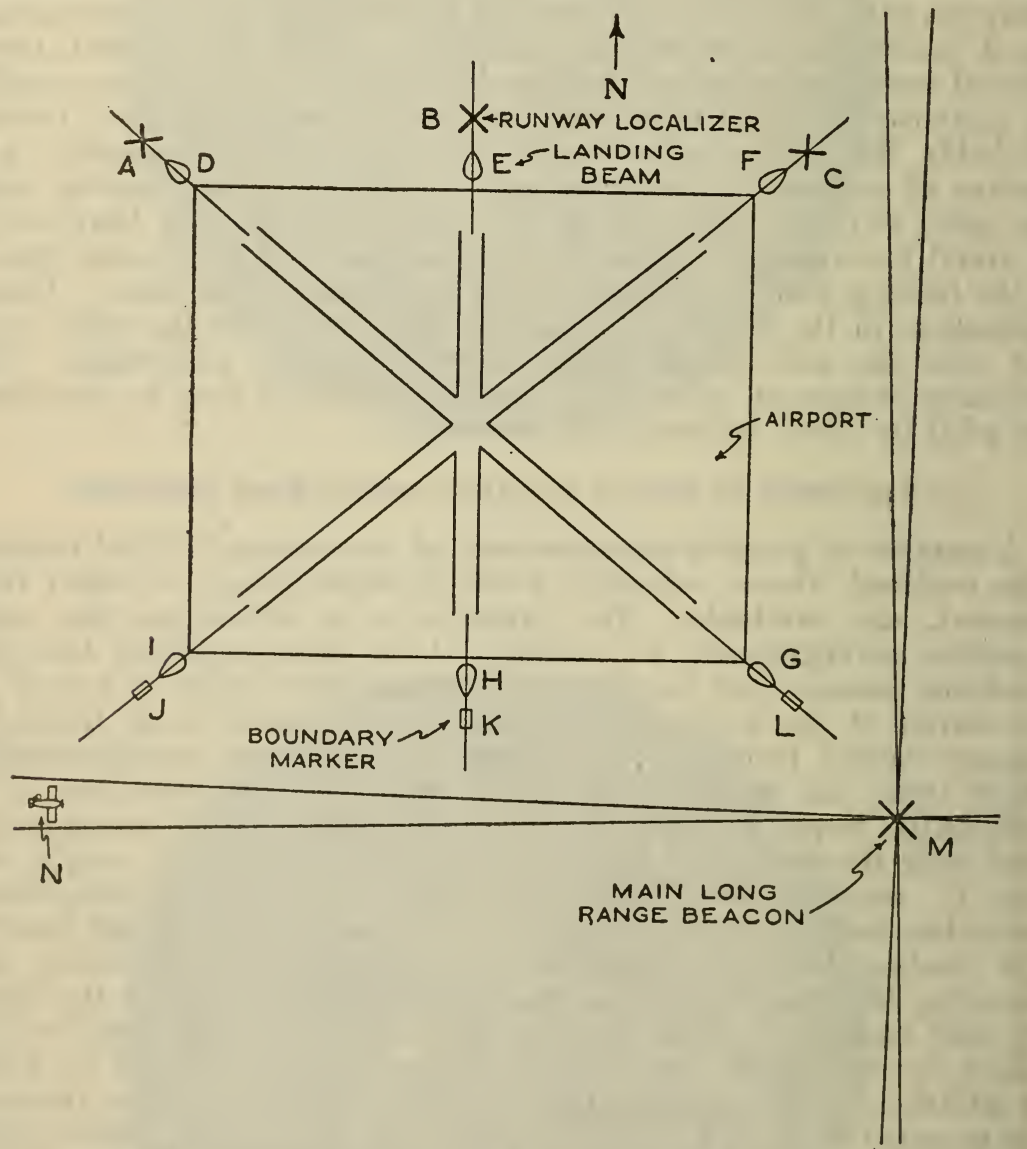

Figure 16.-System of blind landing aids necessary to take care of wind direction on a 3-runway airport

boundary marker beacon, are in operation, being so chosen as to require landing into the wind. In practice, this system would probably be used in the following manner. The radio operator or reserve pilot on an airplane approaching the field on a course of the main radio range beacon $M$, reports to the traffic control officer at the field (by radio) that the pilot. wishes to land. The traffic control officer then informs him of the wind conditions at the field and the direction in which to land. He may also require that the airplane be maintained at a specified altitude in order to permit other air- 
planes to land. This information is relayed to the pilot, who continues on the main radiobeacon course, at the specified altitude, until the drop in deflection of the reed indicator shows that he is passing over the main beacon tower. He then tunes the mediumfrequency receiving set to the runway localizing beacon and, knowing the location of the main beacon relative to the field, heads the airplane on the compass course necessary to follow the particular localizing beacon in operation, in accordance with the information received from the traffic control officer. The pilot continues to travel back and forth along this course at the designated altitude, keeping the position of the field in mind by the zero deflection of the reed indicator each time the airplane passes over the localizing beacon transmitter. When orders are received to land, the radio operator relays the message to the pilot, who follows the localizing beacon course until he is about 5 miles away from the field in the proper direction, makes a $180^{\circ}$ turn so as to head toward the field, places the landing beam receiver in operation, and proceeds to land in the manner described in Section III, 4, in connection with the single runway system.

\section{DESCRIPTION AND OPERATION OF APPARATUS}

In the analysis given above, only such general details of the transmitting and receiving equipment have been introduced as were necessary to the understanding of the system as a whole. In this section the component parts making up the complete system are described in some detail.

\section{RUNWAY LOCALIZING BEACON}

This beacon was briefly described in Section II above. It is essentially a 200-watt, double-modulation beacon, employing small loop antennas so that it may be placed near the landing field without constituting an obstruction to flying. The course indications on the airplane may be obtained either on a reed indicator or on a zero-center pointer-type instrument. For the first case the modulation frequencies used at the beacon are 65 and 86.7 cycles, respectively; in the second case, 60 and 500 cycles, respectively. The beacon apparatus is housed in a 2-story shed located on the border of the landing field and in line with the runway along which the course is to be directed. (See fig. 2.) The transmitting set and machinery are shown on the first floor and the transmitting loop antennas on the second floor. These antennas consist of seven turns of wire wound on frames 6 by 8 feet, the turns being spaced 4 inches apart.

The transmitting set is shown in Figure 17. This transmitter is provided with a 250 -watt power amplifier stage in each amplifier branch, but these stages were not used except in the early tests. The actual transmitting circuit arrangement employed is shown in Figure 18. To simplify apparatus, the transmitter is coupled to the antenna system through two coupling transformers, $C$ and $D$, rather than by means of the goniometer employed in the usual radio range beacon set-up. The variometer $E$ serves to neutralize any residual inductive coupling between loop antennas $A$ and $B$. 


\section{BOUNDARY MARKER BEACON}

The boundary marker beacon is shown in Figure 19. The transmitting loop antenna consists of 10 turns spaced 4 inches apart and wound on a wooden frame 6 by 8 feet, the plane of the antenna being so oriented that the minimum signal zone coincides with the landing field boundary line. In addition to the loop antenna, there are two

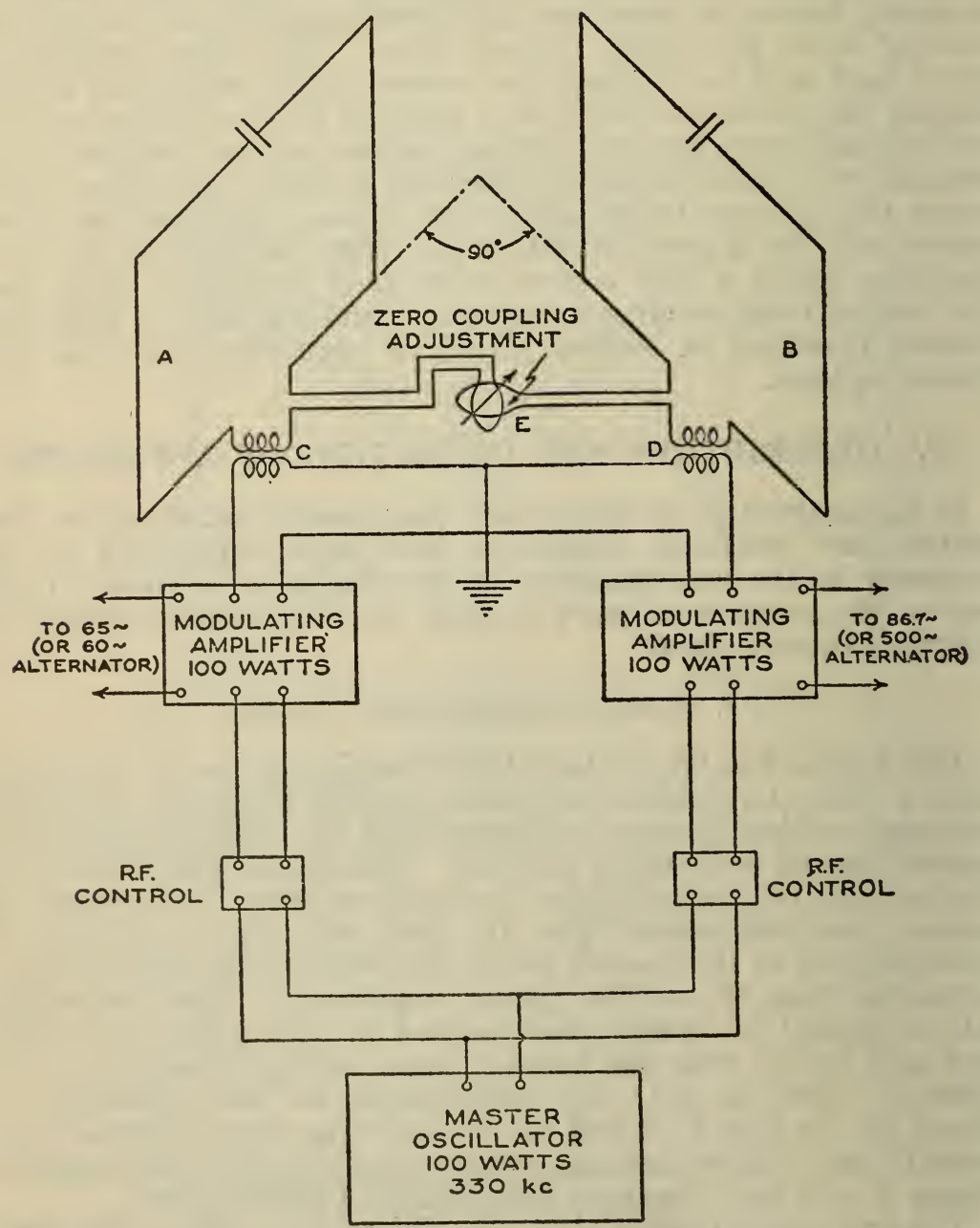

FIGURE 18.-Transmitting circuit arrangement for runway localizing beacon

small weatherproof boxes which contain the power supply unit and the transmitting set. The power supply unit is a converter for changing from 60 -cycle to 500-cycle supply. The transmitting set employs two 50-watt tubes excited alternately from a 500-cycle plate supply transformer and feeding a common oscillatory circuit, coupled inductively to the loop antenna. (See fig. 20:) The tube filaments are also supplied from the 500 -cycle source through a suitable winding 


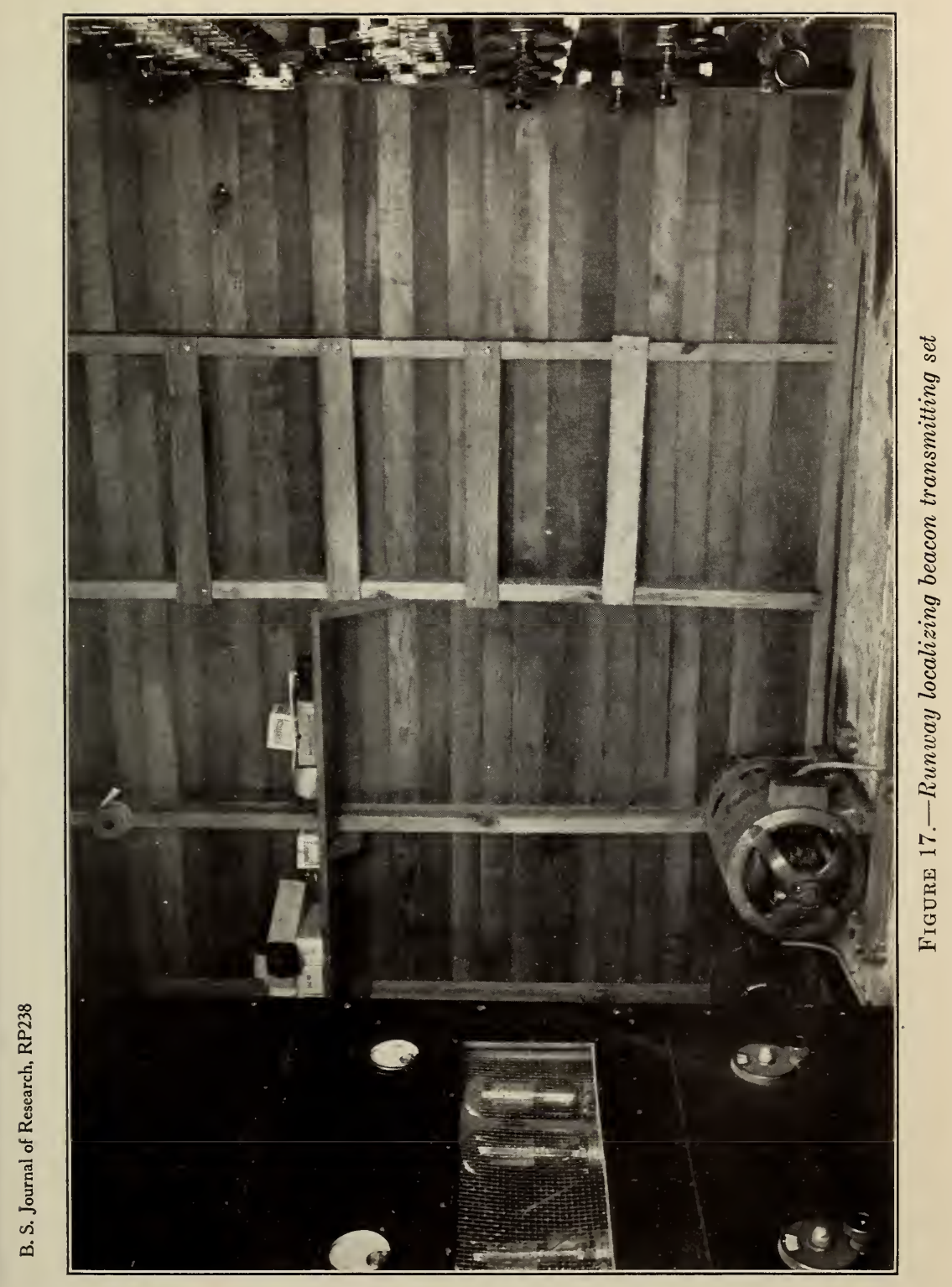


B. S. Journal of Research, RP238

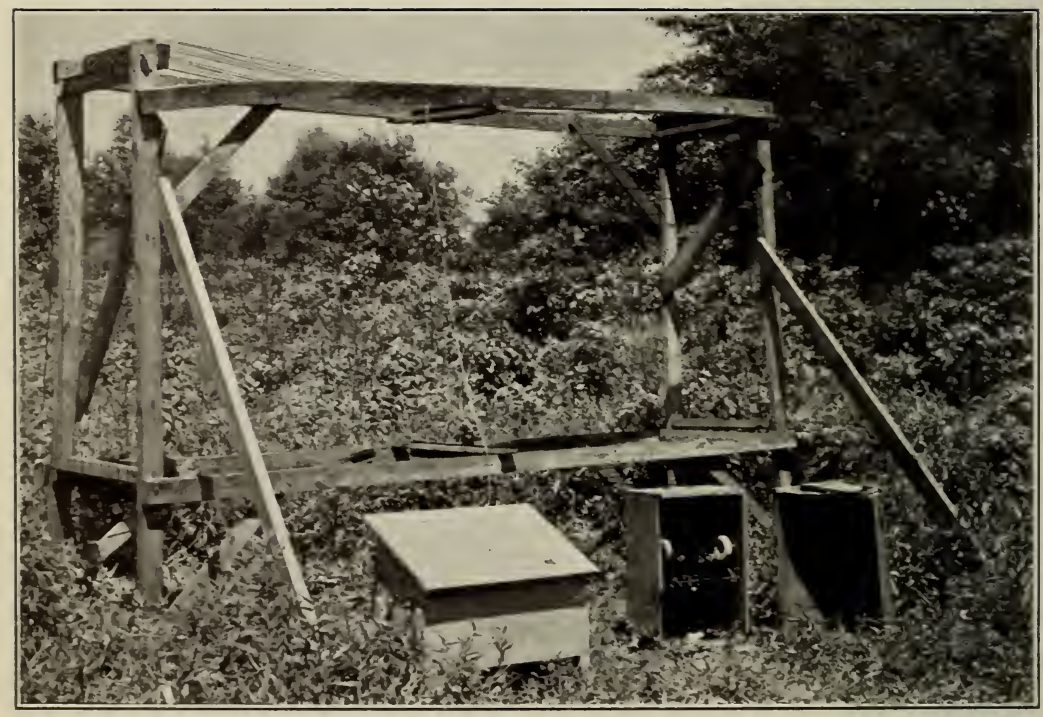

FIGURE 19.-Transmitting system for airport boundary marker beacon 
on the 500-cycle transformer. Due to the alternate excitation of the 50 -watt tubes, the resultant modulation has a frequency of 1,000 cycles. The boundary marker beacon operates on the same carrier frequency as the runway localizing beacon $(330 \mathrm{kc})$.

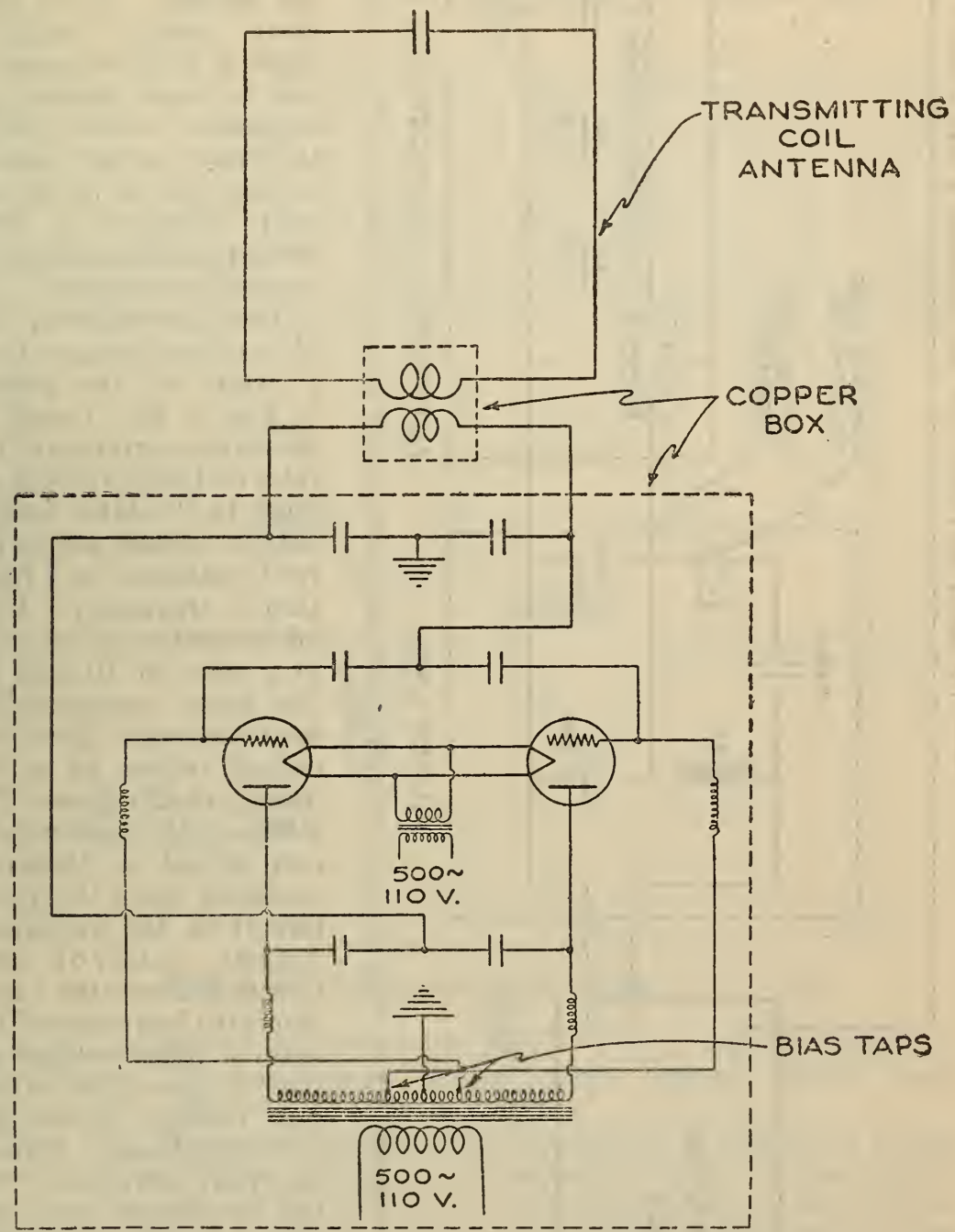

FIGURE 20.-Transmitting circuit arrangement for airport bounciary marker beacon

3. RECEIVING SYSTEM FOR LOCALIZING AND MARKER BEACON SIGNALS

When the vibrating reeds are used as the course indicator on the runway localizing beacon, the receiving system on the airplane is as shown in Figure 21. The filter unit serves to direct the reed frequencies to the reed indicator and the 1,000-cycle marker beacon signals to the head telephones. The automatic volume control is 


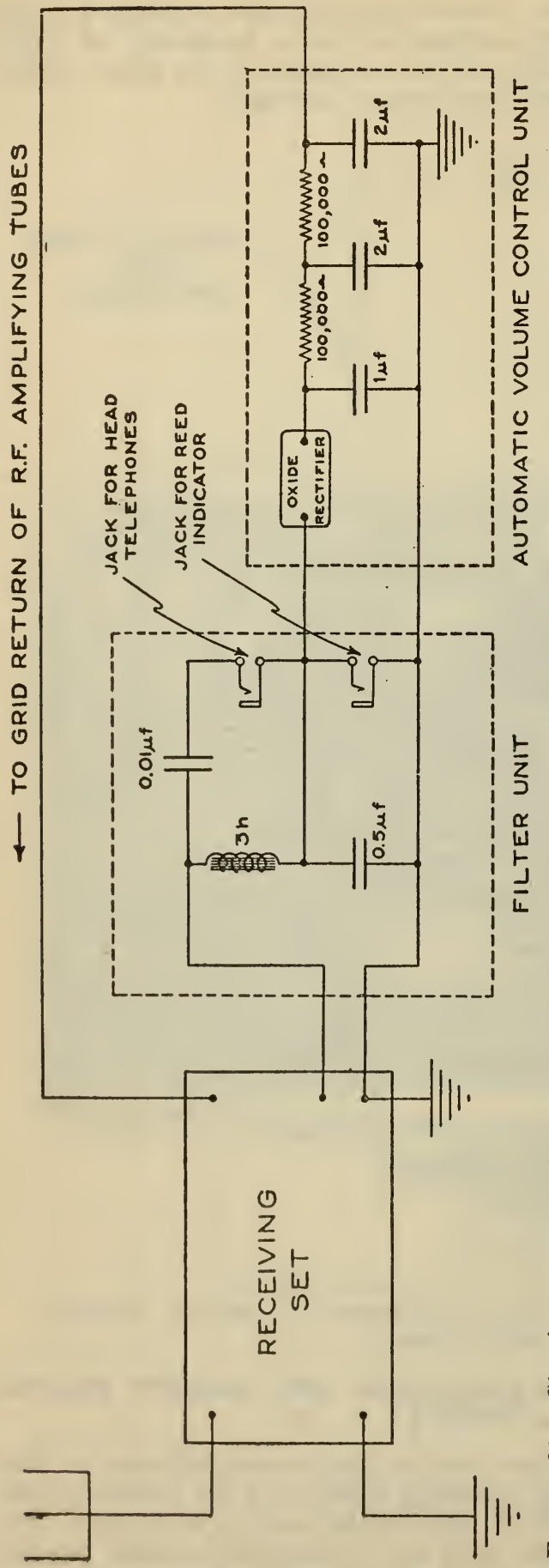

connected across the reed indicator terminals and, consequently, is actuated only by the localizing beacon signals. The 1,000cycle marker beacon signal is therefore permitted to vary through a minimum even though the receiving set output voltage (in so far as the reed indicator is concerned) is maintained substantially constant.

The operation of the filter unit is best seen from a study of the graphs in Figure 22. Graph $A$ shows the variation of the ratio of input voltage applied to the filter unit to output voltage across the reed indicator as a function of frequency. Cutoff is arbitrarily assumed at a value of 10 to 1 for this ratio, corresponding to 20 decibels. Note that cut-off occurs at a frequency of 425 cycles. The 1,000-cycle marker beacon signal is therefore excluded from the input circuit of the automatic volume control unit. Graph $B$ shows the variation with frequency of the ratio of input voltage applied to the filter to output voltage across the head telephones. Cut-off occurs at 140 cycles. The low-frequency reed signals ( 65 and 86.7 cycles) are, therefore, not heard in the head phones. The marker beacon signal is, however, received. In addition, code and intelligible speech may be received without adjustment of the filter unit. 
This is of advantage when the receiving set is used to obtain aural radio range beacon and radiotelephone service on the fixed airways. Graph $C$ shows the variation of the input impedence of the filter unit with frequency. This matches quite well the output impedance of the receiving set employed except in the narrow band, 125 to 300 cycles, which is unimportant.

The operation of the automatic volume control unit in conjunction with the particular receiving set used may be obtained from a study of the graphs in Figure 23. Graph $A$ shows the variation of output voltage across the reed indicator with input voltage to the receiving set when no provision is made for automatic control of volume. Graph $B$ shows the voltage across the reed indicator as a function of the input voltage to the receiving set when the automatic volume control connection is used. The variation of the plate current supply to the radio-frequency amplifying tubes as a function of the receiving

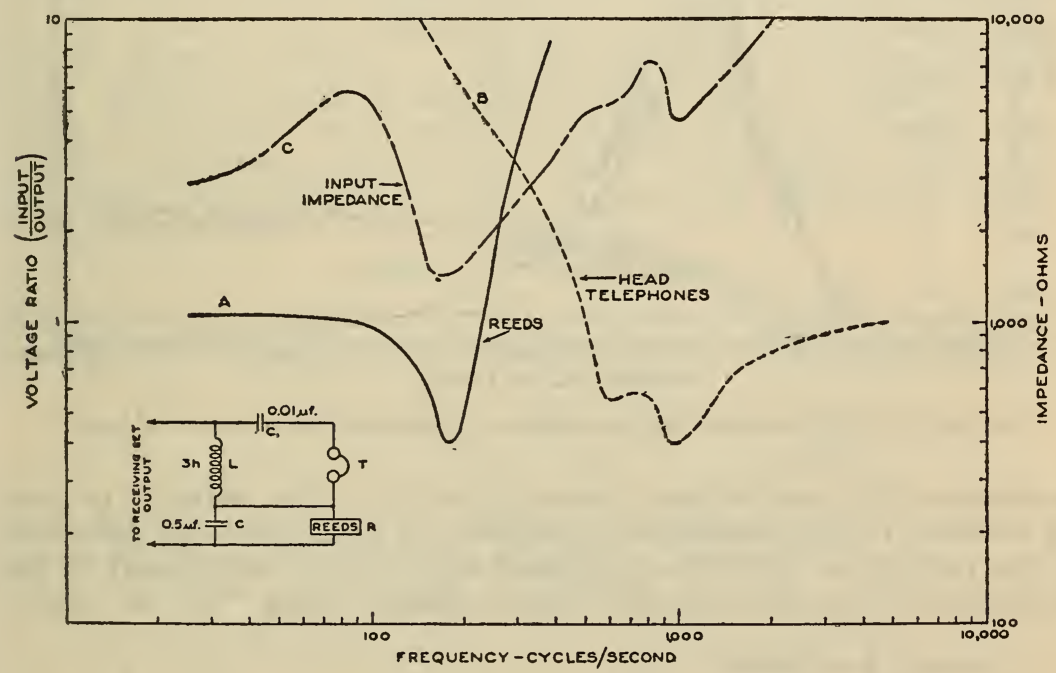

Figdre 22.-Performance characteristics of filter unit

set input voltage is plotted in graph $C$. For a beacon station of given power, the instrument reading plate current supply may, therefore, be calibrated directly in distance.

When the zero-center pointer type instrument is employed as the runway beacon course indicator, a filter-rectifier unit is required at the receiving end for separating the two frequencies of the doublemodulation signal received ( 60 and 500 cycles, respectively), then rectifying the separated signals and applying the resultant rectified voltages in opposition to the instrument terminals. The circuit arrangement for this unit is shown in Figure 24. The receiving set output signal is fed to terminals $A A$ of this unit, the automatic volume control unit being connected across $A A$. Referring to Figure 24, the double-modulation signal is resolved into its component frequencies through circuit $B C$, voltage of 500 -cycle frequency being applied to rectifier $D$, and voltage of 60 -cycle frequency to rectifier $E$. The rectified output voltages from $D$ and $E$ are applied 
in opposition across instrument $F$ by means of the potentiometer $G$, the sliding contact $H$ serving to balance the outputs so that the pointer of instrument $F$ will be in zero-center position when the two

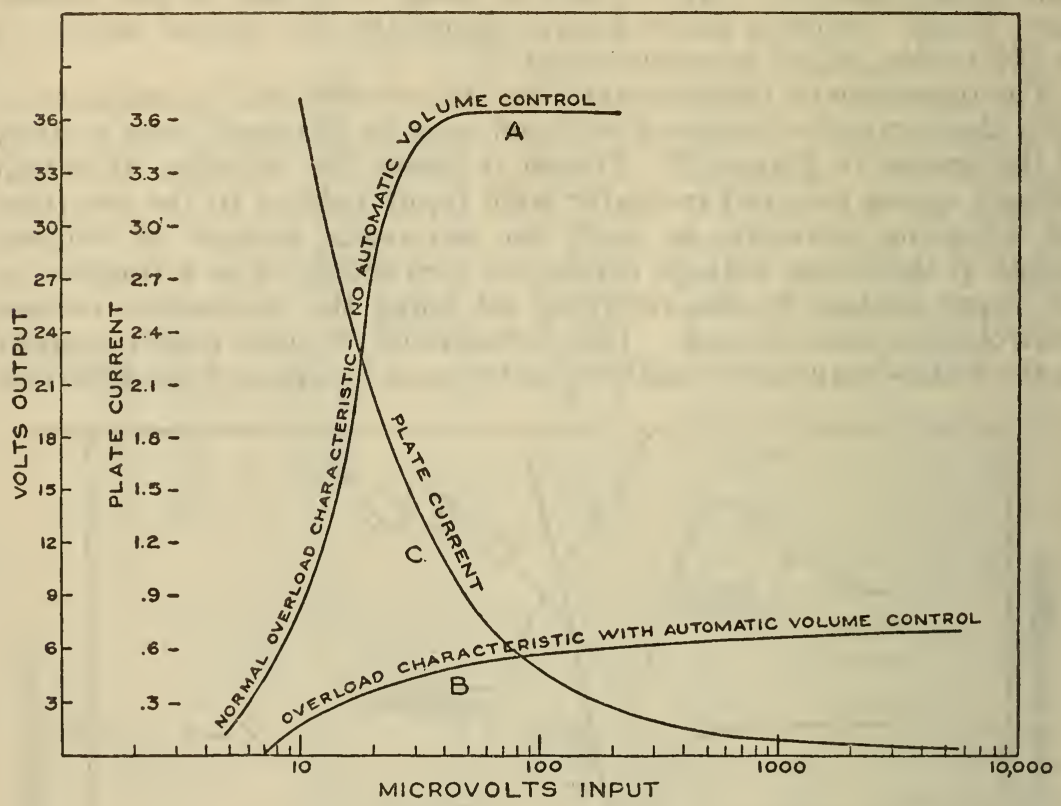

FIgURE 23.-Performance characteristics of automatic volume control unit

modulation frequencies are of equal intensity. The switch $I$ permits the reversal of the instrument terminals, in order that the deflection cf the pointer to the left or right of center may correspond to the direction of deviation from the course, whether flying "to" or "from"

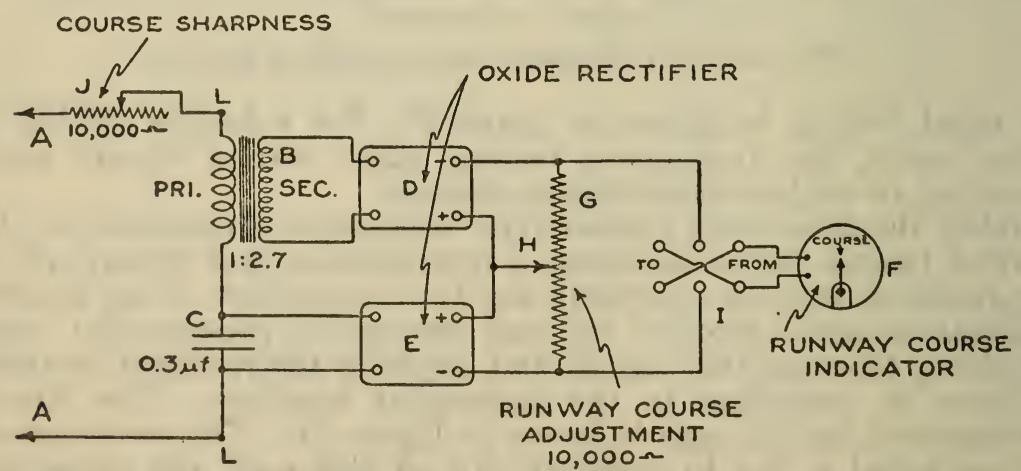

FIGURE 24.-Circuit arrangement for filter-rectifier unit used with pointer type localizing beacon course indicator

the beacon. The indicator $F$ may be made to give any sharpness of course indication above $\pm 0.25^{\circ}$, by varying the intensity of the signal delivered to the terminals $L L$. The series resistance $J$ is 
provided for this purpose. This arrangement permits the use of the same automatic volume control and setting (in parallel with $A A$ ) as is used for the reed indicator when receiving signals from the main radio range beacon.

\section{LAINDING BEAM}

The use of the landing beam was outlined briefly in Section III above. The function of the landing beam is to furnish a pilot with the necessary vertical guidance to permit landing under conditions of no visibility. It consists essentially of a horizontally polarized beam directed at a small angle above the horizontal, this angle and the degree of directivity being so adjusted that a predetermined line of constant field intensity will mark out just the proper gliding path, clearing all obstructions and convenient for landing. In the set-up at College Park, Md., the beam is transmitted on a frequency of $93,700 \mathrm{kc}(3.2 \mathrm{~m})$ and is oriented in the same horizontal direction as the course of the runway localizing beacon. The beam transmitting system is shown in Figure 7. On the airplane, a horizontal dipole antenna feeding a detector-amplifier-rectifier unit is employed for receiving the landing beam signal. As will be evident below, the receiving equipment constitutes essentially a vacuum tube voltmeter arrangement for exploring the field intensity in different portions of the landing beam.

\section{(a) THEORY OF OPERATION}

The polar diagrams of Figures 25 and 26 show, respectively, the horizontal and vertical directive characteristics of the landing beam.

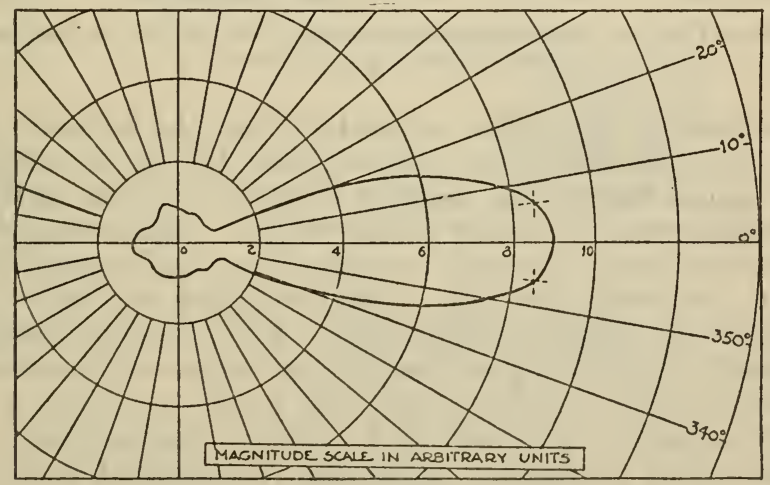

FIGURE 25.-Horizontal divective characteristic of the 93,700 kc landing beam

Referring to Figure 25, and recalling that an airplane is kept along the axis of the beam (in the horizontal plane) by means of the runway localizing beacon, it will be observed that a deviation from the runway course of $\pm 6^{\circ}$ will result in but a 5 per cent drop in the landing beam signals. Since the reed indicator detects a course deviation of $\pm 1^{\circ}$, it may be concluded that an airplane can readily be directed in a horizontal plane, head-on with the beam. In the analysis which follows it will be assumed at all times that the airplane is along the line of maximum intensity in so far as the horizontal characteristic is concerned.

$11295^{\circ}-30-10$ 
Consider now the vertical directive characteristic shown in Figure 26. An airplane flying in a straight line from $B$ to $A$ directly into the region of maximum field intensity of the beam receives a signal which increases inversely as the distance from the beam transmitter. Such a rate of increase in received signal is of little help in landing. Suppose, however, that the airplane is directed into the beam along the line $O C$, until position $G$ is reached, at which point the indicating instrument on the airplane reaches half-scale deflection. At a point directly above $G$, this deflection increases, since the airplane is nearer the line of maximum intensity of radiation of the beam. At a point directly below $G$, the deflection decreases, the airplane now being farther from the line of maximum intensity of radiation. The instrument deflection thus increases or decreases with any increase or decrease in the altitude of the airplane about the point $G$. If, now, a straight line were followed from $G$ to $A$, the indicating instrument pointer would soon go off scale due to the approach of the receiving system to the transmitting source. However (and this is the basis of operation of the system), by dropping away from the line of maximum intensity of radiation as $A$ is approached, the instrument pointer may be held at the half-scale deflection position at all times,

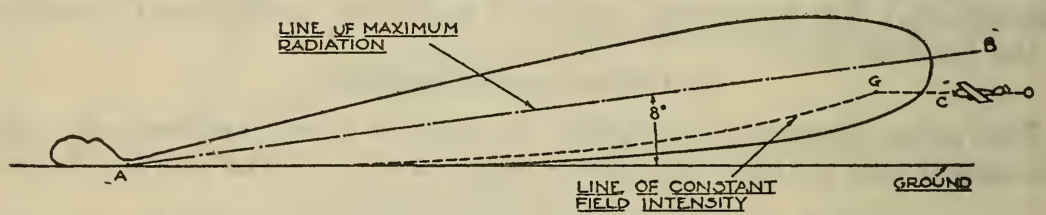

FIGURE 26.-Vertical directive characteristic of the $93,700 \mathrm{kc}$ landing beam showing landing glide path

since the increase in signal due to the fact that the airplane is nearing the source $A$ is continuously compensated for by a corresponding decrease in signal due to the angular departure of the airplane from the line of maximum intensity of the beam. The path followed by holding the instrument pointer constantly at half-scale deflection is indicated by the dotted line $G A$. Obviously this is a line of constant field intensity of definite magnitude. By properly orienting the beam vertically and giving it the proper degree of directivity, this line of constant field intensity may be made to coincide with the landing path normally followed by a pilot in clear weather.

This glide curve or landing path may be derived from a proper combination of two graphs, one of which shows the inverse variation of field intensity with distance from the beam transmitter, and the other the polar curve showing the beam directivity in the vertical plane. Referring to Figure 27 which shows the same vertical characteristic as Figure 26, the line of maximum intensity of radiation of the beam $(O K)$ makes an angle of $8^{\circ}$ with the horizontal. Assume that the field intensity at a point located on this line and 2,000 feet horizontally distant from the transmitter is 2,000 (in arbitrary units $\left.{ }^{10}\right)$. This corresponds to the magnitude $O K$. Then the field intensities at points the same horizontal distance from the transmitter

10 These units are chosen to correspond to the reading of the landing beam indicating instrument in microamperes. This assumes that the detector-amplifier-rectifier is essentially linear in operation. 
but located on lines making, respectively, $4^{\circ}, 2^{\circ}$, and $1^{\circ}$ with the horizontal, correspond to the magnitudes $O L, O M$, and $O N$, and are equal to $1,840,1,600$, and 1,200 (in the same arbitrary units). Consider, now, the variation of field intensity, along each of the lines

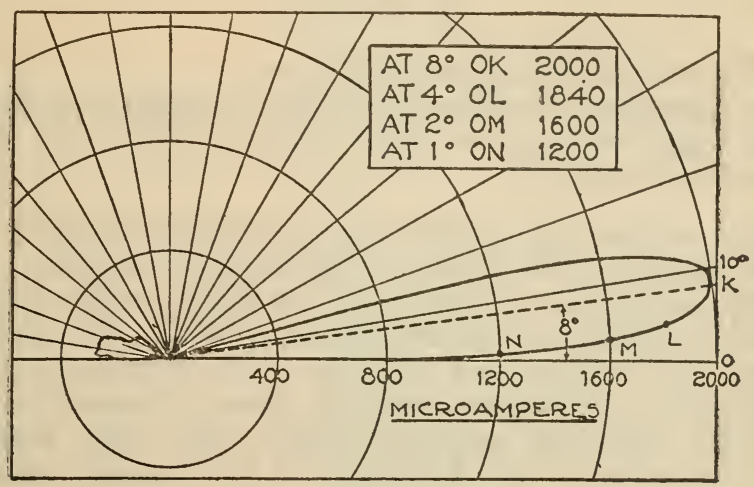

FIgURe 27.-Vertical directive characteristic of the 93,700 kc landing beam giving experimental data used in the graphical determination of the landing glide path shown in Figure 29

considered, for increasing distance from the transmitter. The graphs corresponding to the lines making $8^{\circ}, 4^{\circ}, 2^{\circ}$, and $1^{\circ}$ with the horizontal are shown, respectively, by $K, L, M$, and $N$ in Figure 28. In each case the field intensity is an inverse function of the distance. To

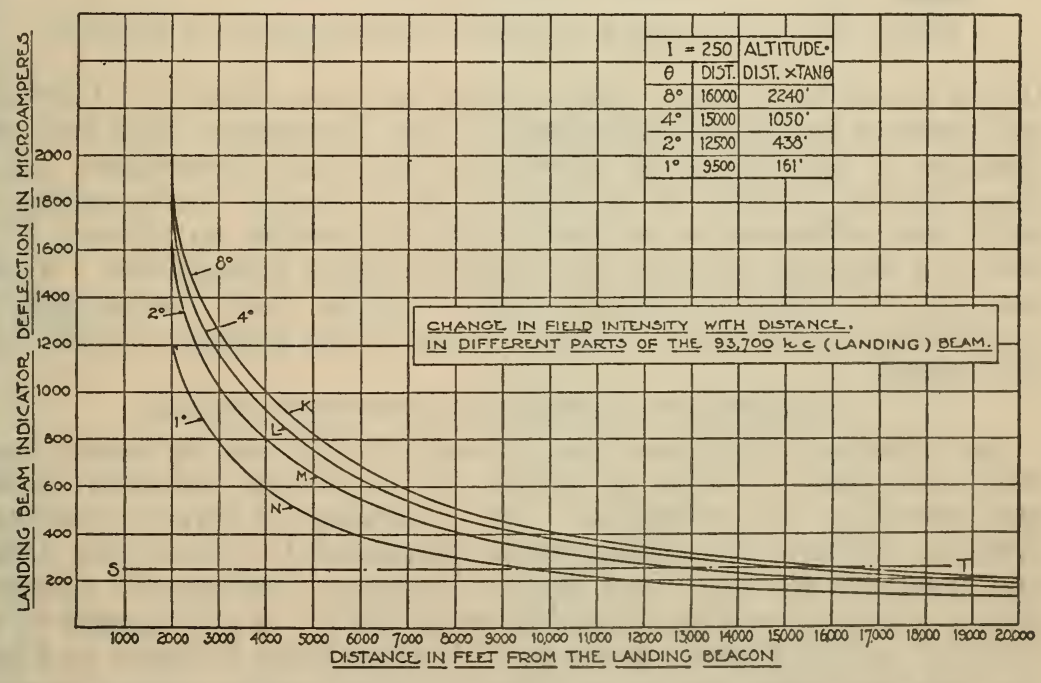

FIGURE 28.-Graphical method of determining landing glide path from the data given in Figure 27

determine the shape of any line of constant field intensity it is now simply necessary to draw a horizontal line, such as $S T$ corresponding to the intensity desired ( 250 in this case, half-scale reading of the microammeter used in practice), determining the horizontal distance 
from the transmitter corresponding to the points of intersection of this line with the graphs $K, L, M$, and $N$, and computing the height of these points above the ground from the relation

where

$$
h=d x \tan \theta
$$

$h$ is the height above ground in feet,

$d$ the horizontal distance from the transmitter in feet,

$\Theta$ the angle between the lines $O K, O L, O M, O N$ (fig. 27), and the horizontal.

Four points on the graph shown in Figure 29 are thereby determined. This is the landing path which it was required to find.

A second method for determining the glide curve corresponding to a given field intensity is indicated in Figure 30. The field intensities are plotted as abscissas and altitude of the airplane as ordinates at each 1,000 feet of distance from the beam transmitter. The data plotted were obtained experimentally, the field intensity being measured in terms of the deflection of the landing beam indicator.

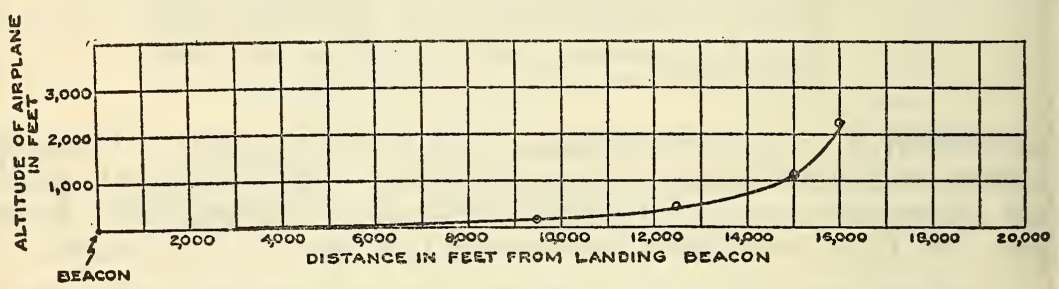

FIgURE 29.-Landing glide path derived from data given in Figure 27

It will be observed that a pilot coming in at an altitude of 1,000 feet will observe half-scale deflection of his instrument $(250 \mu \mathrm{a})$ at a distance of approximately 9,000 feet from the transmitter. If he then follows the line of constant field intensity corresponding to half-scale deflection on his instrument, he reaches an altitude of 10 feet at a distance of 2,000 feet from the beam transmitter. This is actually the point of contact of the airplane with the ground, the receiving antenna being mounted on top of the airplane, 10 feet from the ground.

(b) DIRECTIVE TRANSMITTING ANTENNA SYSTEM

An ultrahigh frequency was chosen for the landing beam transmitting system in order to secure the attendant reduction in size and simplicity of equipment. Of a number of directive antenna systems studied, the arrangement developed by Unda and Okabe and described by Yagi, ${ }^{11}$ for the production of horizontally polarized directed beams, was considered most suitable. A photograph of the directive antenna array, as set up at College Park, is shown in Figure 7. This was later housed in a shed for protection against weather. The ultrahigh frequency source $(93,700 \mathrm{kc})$ is coupled to the horizontal $\operatorname{doublet} A$ (made of $1 / 8$-inch copper tubing), which serves as the radiating 'antenna and is accurately tuned to the frequency of the source. About $0.8 \mathrm{~m}$ behind the radiating antenna is placed a reflecting

.11 Hidetsugi Yagi, Beam Transmission by Ultrashort Waves, Proc. I. R. E., 16, p. 715; 1928. 
antenna $B$, also a horizontal doublet, tuned to a frequency somewhat lower than the frequency of the source. At approximately every meter in front of the radiating antenna, horizontal-doublet directing antennas $C$ are placed. These are tuned to a frequency somewhat higher than that of the source. This array of antennas is supported on a horizontal wooden structure $D$, approximately $2.75 \mathrm{~m}$. above the ground, and pivoted on the vertical support $E$. To obtain the vertical directive characteristic shown in Figure 27 , the wooden structure $D$ was tilted approximately $8^{\circ}$ above the horizontal.

\section{(c) THE ULTRAFIGH-FREQUENCY TRANSMITTING CIRCUIT ARRANGEMENT}

The problem of obtaining sufficient power output on the high frequency used was found to be a rather difficult one. Sufficient radiation was desired to operate a visual indicating device at a distance of 5 to 8 miles from the source with not more than two tubes in the receiving set. The necessary power output was secured through the use of a 500-watt three-element tube (General Electric ZP-2) used in the oscillatory circuit shown in Figure 31 . This circuit arrange-

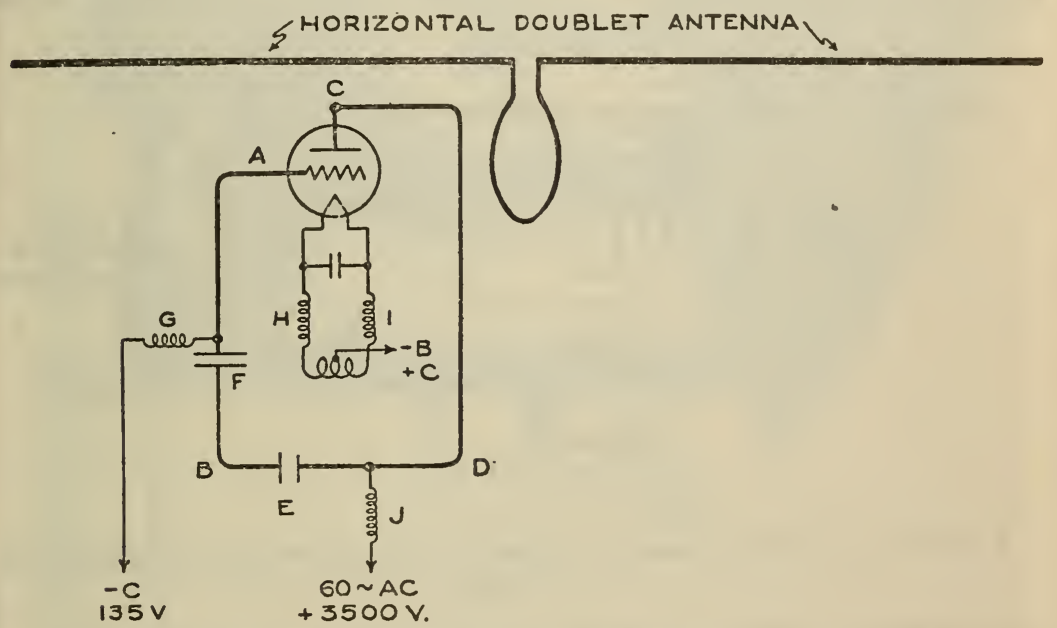

Figure 31.-Circuit diagram of $93,700 \mathrm{kc}$ landing beam oscillator

ment has the advantage obtained in the customary short wave twotube push-pull circuit where the two tube capacities aro in series, thereby halving the total tube capacity in the circuit. In this new oscillatory circuit the second tube is replaced by a small air condenser $E$, with a capacity about equal to the interelectrode grid to plate capacity of the tube. The plate inductance $C D$ and the grid inductance $A B$ are placed between this condenser and the tube, the leads making the shortest possible connections between these elcments of the circuit constituting the inductances. Condenser $F$ is of relative large capacity and is necessary only as a safety measuro in case of flashover of condenser $E . \quad G, H, I$, and $J$ are suitable cholie coils to keep the oscillatory current out of the power supply leads.

Figure 32 shows the 500-watt tube and associated apparatus, including the horizontal doublet radiating antenna. The tube is oper- 
ated with 3,500 volts of 60 -cycle frequency on the plate and a negative grid bias of about 135 volts. The tube circuit is tuned to the desired frequency within narrow limits by moving one of the plates of condenser $E$ by means of an insulated adjustment screw. The frequency has proved sufficiently stable for use without external means for frequency control, due in part to the fact that but one broadly tuned circuit is used at the receiving end.

\section{(d) THE RECEIVING SYSTEM}

Considerable time was devoted to the development of a simple and reliable receiving system for giving visual reception of the directed beam up to a distance of 5 to 8 miles. Early in the work it was found that by placing a receiving tube in the center of a horizontal doublet antenna, rather broad tuning was obtained. This was quite desirable since slight changes in the transmitting frequency or receiving antenna constants then had no effect on the deflection of the receiving indicating instrument.

The circuit arrangement finally found to be the most stable and reliable as well as sensitive (see fig. 33) uses only two tubes without

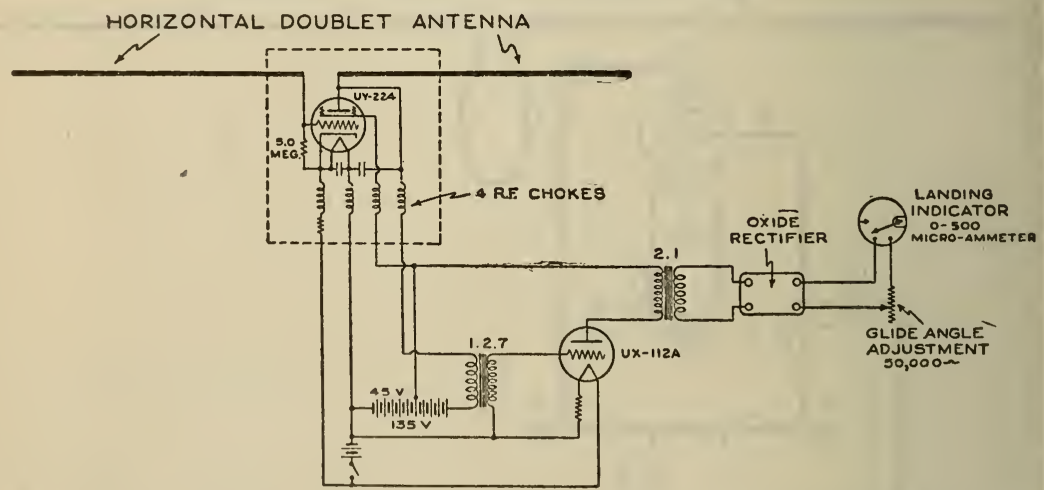

FIGURE 33.-Circuit diagram of special ultrahigh-frequency landing beam receiving set

regeneration. This receiving circuit requires no adjustments on the part of the pilot. Even the volume control is dispensed with, since the path followed during the use of the receiving set constitutes a line of constant field intensity of the directed beam. The detecting portion of the receiving circuit (within the dotted lines) is external to the airplane, being mounted in a streamline weatherproof box about 14 inches above the top wing. (See fig. 8.) The doublet antenna is in the form of two copper rods housed in wooden streamlined supports projecting from the streamlined detector box. The rest of the apparatus, which includes the audio amplifying tube and transformer, oxide rectifier, $\mathrm{A}$ and $\mathrm{B}$ batteries, and indicating instrument, are located within the airplane.

Figure 34 at $A$ shows an inside view of the streamlined detector box. The amplifier-rectifier unit is shown in Figure 34 at $B$. The oxide rectifier shown eliminates one tube, and has been found perfectly stable in its operation at the low frequency employed. 


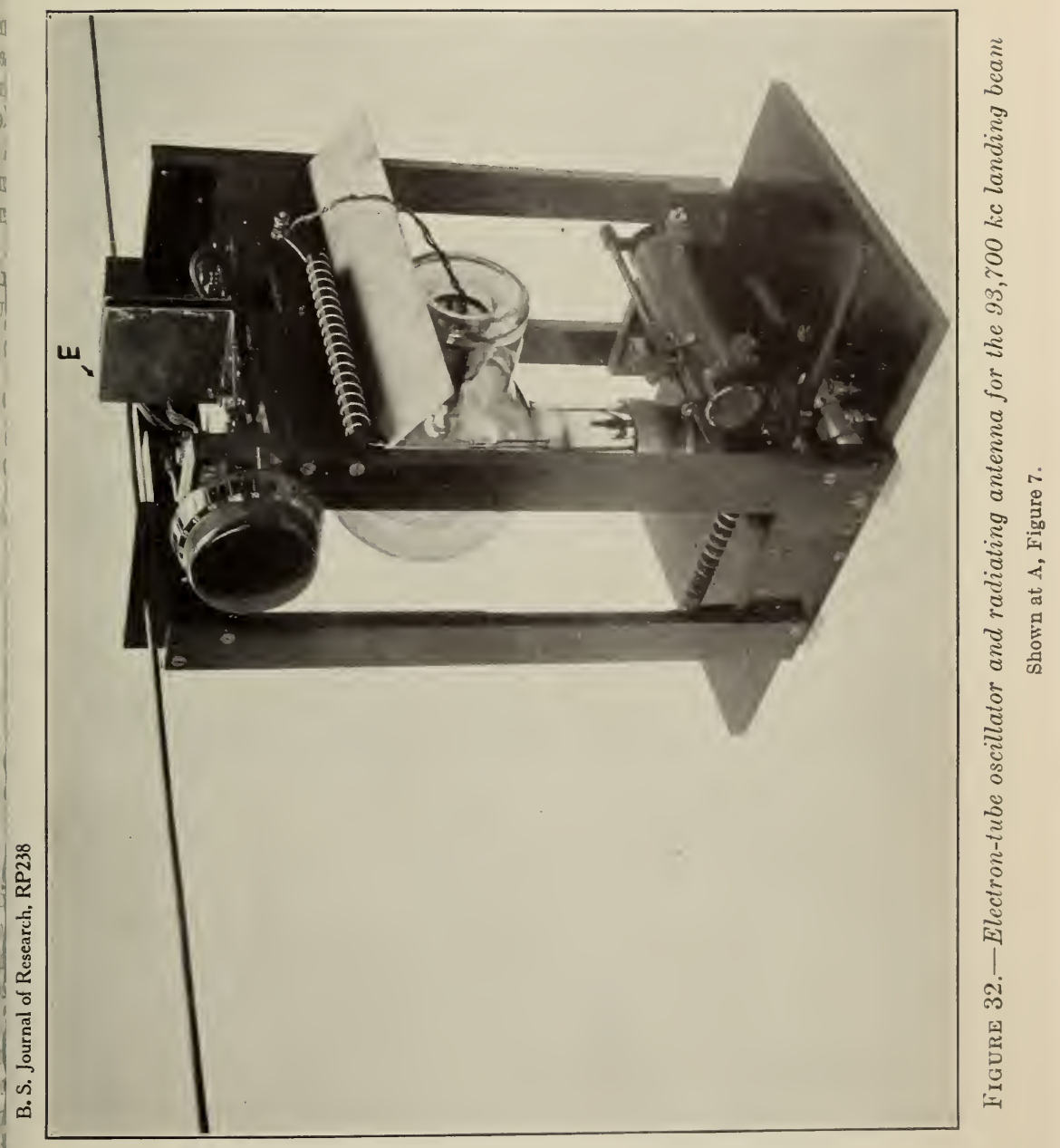




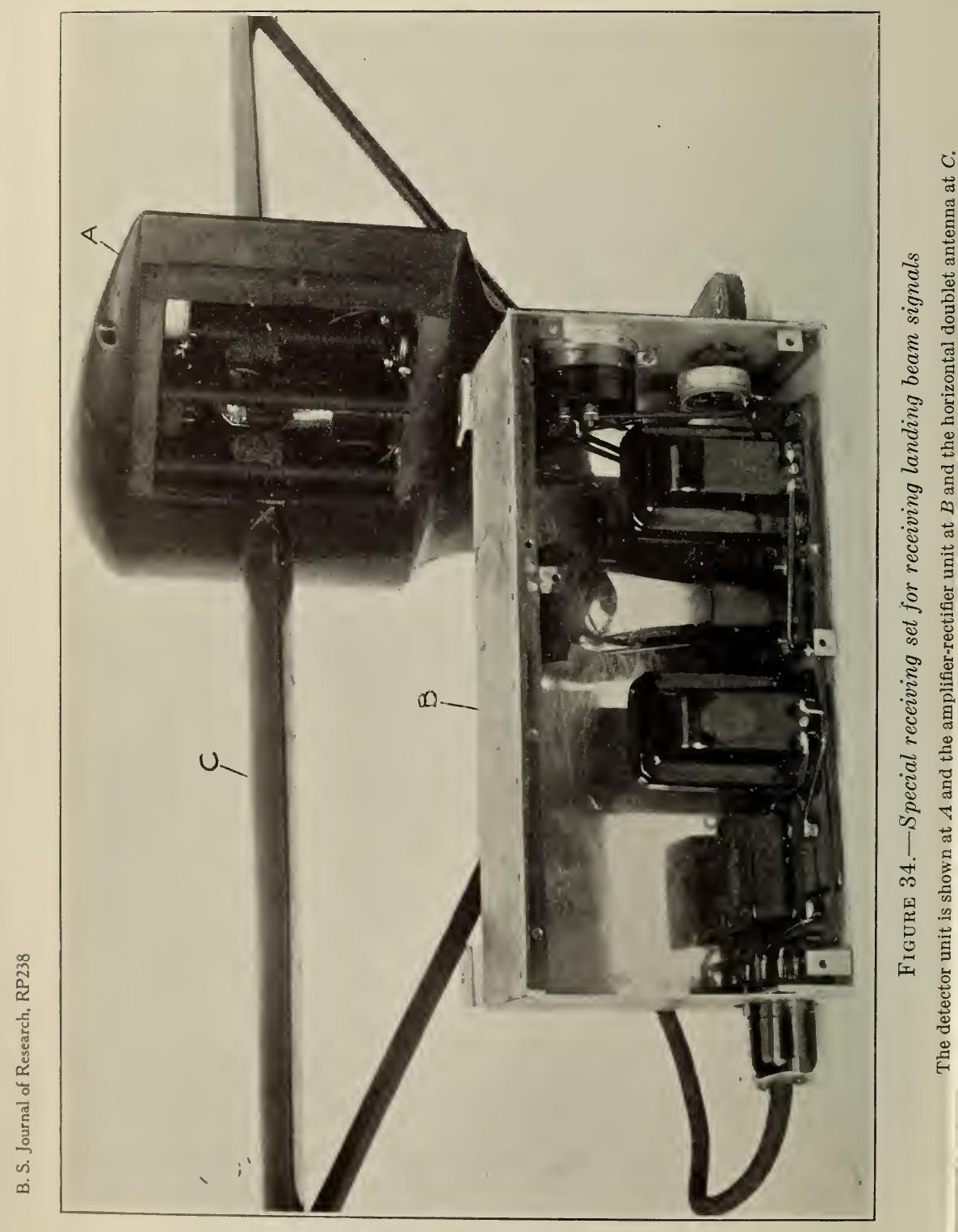


A 224 heater-type screen-grid tube is employed for the detector, to afford the necessary high amplification without undue microphonic noises. To obtain good efficiency it was found desirable to connect the detector tube directly in the center of the horizontal doublet antenna. The detector tube was, therefore, located about 1 inch from the center of the antenna. The radio-frequency porticn of the circuit is confined to the section above the four radio-frequency chokes. (See fig. 33.) The four leads running from the lower side of these chokes carry either direct current or the received audio modulation. The streamlined detector box and antenna system is arranged to plug in electrically to the supporting upright on the wing, a five-terminal plug making the necessary connections. The supporting upright also makes a plug connection to a socket in the wing.

Figure 35 shows the complete wiring diagram for the landing beacon receiver. It will be noted that the pilot has a small control box with a switch for controlling the receiving set filaments and a push button which operates a buzzer mounted in the detector box. The purpose of this buzzer is to produce a signal which operates the microammeter, provided the complete receiver is functioning properly. This button is pressed once before each landing to insure that the receiving set is functioning properly.

\section{PRACTICAL APPLICATIONS}

The practicability of the radio system of blind landing aids described has been partially demonstrated in numerous test flights on the bureau's experimental airplane. No difficulty has been experienced in following both the runway localizing beacon and the landing beam indications simultaneously. These tests have, however, all been made under conditions of good visibility, the bureau's airplane not being adapted for "blind" flying work. Arrangements are now being made for actual blind landing tests, the results of which it is felt will completely demonstrate the feasibility of the system.

Even in its simplest arrangement (see fig. 6), which does not take care of wind direction, this system should have numerous applications to scheduled flying. It should successfully prevent practically all interruptions to scheduled service due to dense fog, since fog is rarely accompanied by strong winds. Under special conditions of low visi-) bility (for example, when the airport has a ceiling of 100 feet or more) the system may be used as an aid to landing regardless of wind conditions. A particularly interesting application consists of the use of this system for complete or partial blind landing on sea dromes or on airplane carriers, where the landing deck can at all times be oriented into the wind. A large number of conditions exist where a partial use of the system described appears practicable. The runway localizing beacon, in particular, seems to have possibilities of extensive use. This was demonstrated in the tests at Mitchel Field, under the auspices of the Guggenheim fund, where a special landing altimeter was employed in conjunction with the localizing beacon.

With the expansion of the system to take care of wind direction as shown in Figure 16, it is felt that the last great obstacle to flying under any conditions of weather is overcome. 


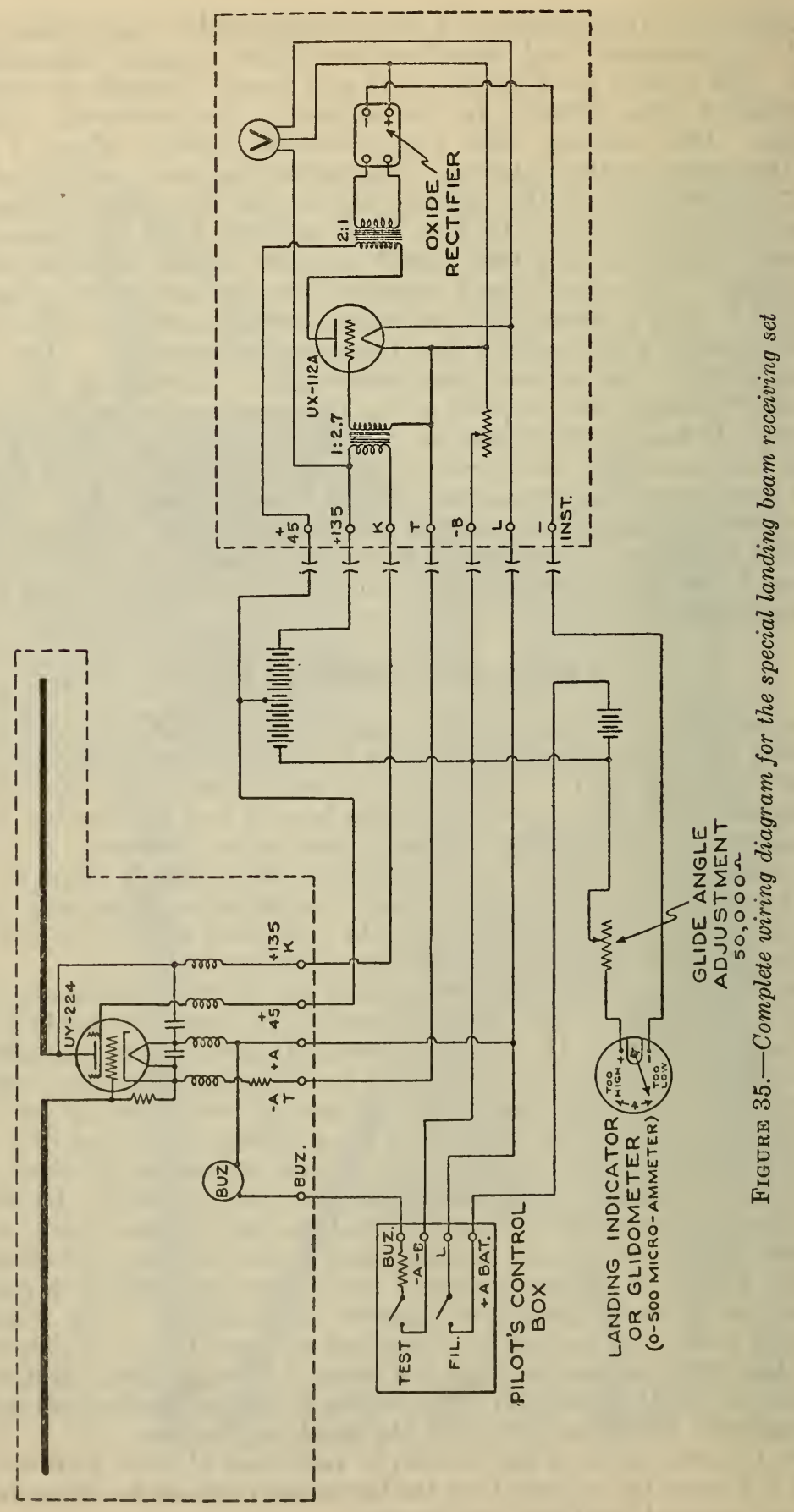




\section{ACKNOWLEDGMENT}

The authors desire to acknowledge the parts played in this development by their coworkers in the Bureau of Standards. Appreciation of valuable contributions is extended to Lieut. D. H. Stuart, airplane pilot, for skillful flight tests of the system; to W. II. Orton for research incident to the operation of the landing transmitting and receiving apparatus; to W.S. Hinman for research in the design and construction of the automatic volume control and filter units; and to F. G. Kear and R. M. Green for field installations and tests. Special acknowledgment is due to Col. H. H. Blee, director of aeronautic development, Aeronautics Branch, and Dr. J. H. Dellinger, chief of the radio section, Bureau of Standards, for many helpful suggestions during the progress of the work.

Washington, July 29, 1930. 